\title{
Substitution between Fixed-line and Mobile Access: the Role of Complementarities*
}

\author{
Lukasz Grzybowski ${ }^{\dagger} \quad$ Frank Verboven ${ }^{\ddagger}$
}

August 2015

\begin{abstract}
We study substitution from fixed-line to mobile voice access, and the role of various complementarities that may slow down this process. We use a rich survey data of 160,363 households from $27 \mathrm{EU}$ countries during 2005-2011. We estimate a discrete choice model where households may choose one or both technologies, possibly in combination with internet access. We obtain the following main findings. First, there is significant fixed-to-mobile substitution, especially in recent years: without mobile telephony, fixed-line penetration would have been 14.1\% higher at the end of 2011. But there is substantial heterogeneity across households and EU regions, with a stronger substitution in Central and Eastern European countries. Second, the decline in fixed telephony has been slowed down because of a significant complementarity between the fixed-line and mobile connections offered by the fixed-line incumbent operator. This gives the incumbent a possibility to protect its position in the fixed-line market, raising market share by $2.7 \%$, and to leverage it into the mobile market, raising market share by $5.4 \%$ points. Third, the decline in fixed telephony has also been slowed down because of the complementarity with broadband internet: the introduction
\end{abstract}

*Financial support from the NET Institute, www.NETinst.org is gratefully acknowledged. We thank Marc Bourreau, Yutec Sun, Steffen Hoerning and participants at the 2014 ICT Conference at Telecom ParisTech, 2014 FSR C\&M scientific seminar at the Florence School of Regulation, 12th Annual IIOC Conference in Chicago and 2014 CRESSE Conference in Korfu for helpful comments. All errors are our own.

${ }^{\dagger}$ Telecom ParisTech, Department of Economics and Social Sciences, 46 rue Barrault, 75013 Paris, France. E-mail: lukasz@mushroomski.com

${ }^{\ddagger}$ University of Leuven and CEPR (London), Naamsestraat 69, 3000 Leuven, Belgium. E-mail: Frank.Verboven@kuleuven.be 
of DSL avoided an additional decline in fixed-line penetration of $8.7 \%$ points at the end of 2011. The emergence of fixed broadband has thus been the main source through which incumbents maintain their strong position in the fixed-line network.

Keywords: fixed-to-mobile substitution; incumbency advantage; broadband access JEL Classification: L13, L43, L96 


\section{Introduction}

At the start of the 1990s, telecommunications industries in the European Union were controlled by state monopolies which transmitted phone calls using the fixed-line copper network. There were a small number of mobile phone users via analog networks $(1 \mathrm{G})$, which in most of the EU countries were operated by the subsidiaries of the fixed-line incumbents. This situation changed dramatically during the last two decades. First, in the early 1990s several competing mobile operators started to deploy voice services based on second generation (2G) technologies GSM900 and DCS-1800. Second, after the liberalization in the EU in 1998 a large number of entrants started providing voice services through the incumbents' fixed infrastructure. Third, in the late 1990s the deployment of internet broadband services started, which initially also mainly relied on fixed-line copper networks.

With the deployment of these new technologies the number of communication options increased. This influenced the way in which people communicate, in particular how they use copper-based fixed-line connections. The rapid increase in the number of mobile users was paralleled with a decline in the number of fixed-line subscribers. At the same time, the effect of broadband deployment on the usage of fixed-line connections is less obvious. Broadband internet access was first deployed using digital subscriber line technology (DSL). This relied on copperbased networks and required consumers to maintain their fixed-line connections. In most of the EU countries, DSL is still a dominant broadband technology. But there are also countries, especially in Central and Eastern Europe (CEE), where alternative broadband technologies, such as cable, fibre and mobile broadband, obtained significant market shares.

In this paper we analyze the substitution between fixed-line and mobile voice services, and the role of several complementarities that may influence this process. In particular, we ask whether and how the incumbent fixed-line operators managed to slow down fixed-to-mobile substitution, and whether they could leverage their position from fixed to the mobile voice services. Furthermore, we ask to what extent broadband internet slowed down fixed-to-mobile substitution. Addressing these questions is important since fixed-to-mobile substitution affects the financial viability of the incumbent fixed-line operators. It is therefore critical for both the operators and industry regulators to understand the interdependencies between different communication technologies. The question of fixed-to-mobile substitution is also important 
because of the ongoing consolidation process in telecommunications markets. There is a growing number of mergers between mobile operators which need to be scrutinized by the competition authorities, and substitution between fixed-line and mobile services should play an important role in the market investigations.

To address these questions, we make use of a unique micro-level dataset of 160,363 households from 27 EU countries during the period 2005-2011. We adapt the model of Gentzkow (2007) to analyze the situation in which households may choose bundles of different technologies: fixed voice or mobile voice only, or the combination of both services, with or without broadband internet. We can summarize our results in three main findings.

Our first main finding is that households tend to perceive mobile and fixed-line connections as substitutes, and more strongly so in the recent years. In 2006 total fixed-line penetration in the EU was almost $67 \%$, and it would have been $5.9 \%$ points higher if mobile voice had not been present. At the end of 2011 total fixed-line penetration was about $63 \%$, and it would have been almost $14.1 \%$ points higher without mobile voice access. At the same time, there is substantial heterogeneity across households and regions. In regions with a higher GDP per capita mobile and fixed-line services tend to be stronger substitutes. After controlling for GDP per capita, there is also a stronger degree of substitution in the CEE countries, as compared to the WE countries. There is not only heterogeneity in fixed-to-mobile substitution across regions, but also across households with different age, education, professional activity, etc. This implies that even within a region, some households may perceive fixed-line and mobile connections as very strong substitutes, whereas other households perceive them as essentially independent. Our finding of strong heterogeneity in the perceived substitutability between fixed-line and mobile voice services provides an explanation for the mixed results found in the previous literature that uses aggregate data. ${ }^{1}$

\footnotetext{
${ }^{1}$ For instance, Gruber and Verboven (2001) estimate a logistic diffusion model for mobile subscriptions in the $\mathrm{EU}$ and find that the penetration rate of fixed telephony has a negative influence on the diffusion of mobiles. On the other hand, Gruber (2001) uses a similar approach for the Central and Eastern European countries and suggests that mobile and fixed-line services may be complements. In another paper, Hamilton (2003) uses data for African countries finds that mobile and fixed-line subscriptions may be both complements and substitutes at different stages of market development. In the early stage of diffusion, mobile services may complement fixed-line telephones but the substitution effect takes over once mobile usage becomes more widespread.
} 
Our second main finding relates to the role of the incumbents, i.e., the previous fixed-line monopolists, in slowing down the extent of fixed-to-mobile substitution. To investigate this, we extend our base model and estimate it using data for the years 2005 and 2006. For these years, we observe whether households have fixed and/or mobile voice at the incumbent or at a competitor. This enables us to consider the simultaneous choice of fixed and mobile voice, at the incumbent or a competitor. We confirm the presence of fixed-to-mobile substitution in this model. Furthermore, we find that the decline in fixed-line penetration has been slowed down because of various complementarities: bundled contracts and especially incumbency advantages when fixed-line incumbents are also active in mobile telephony. These incumbency advantages increased the incumbent's market share by about $2.7 \%$ points in fixed telephony and by up to $5.4 \%$ points in mobile telephony at the end of 2006 . Incumbents could thus not only slow down the fixed-to-mobile substitution process, but also leverage their strong position in fixed telephony into the mobile telephony market. These complementarities do not hurt, but actually benefit total fixed and mobile penetration.

Our third main finding relates to the impact of broadband internet on fixed-to-mobile substitution. To assess this, we further extended the model to consider the simultaneous choice of fixed versus mobile voice services and the choice of broadband technology (no broadband, dial-up, DSL, cable, mobile broadband and other). Also in this model specification we confirm the presence of significant fixed-to-mobile substitution, especially in the recent years. In addition, we find that the introduction of mobile broadband slightly strengthens this substitution. But more importantly, broadband internet (mainly DSL) has been a strong source of complementarity with fixed-line telephony. Hence, the decline of fixed telephony has been slowed down because of the complementarity between the fixed network and broadband internet. In particular, without DSL fixed-line voice penetration would have been about $6.3 \%$ lower at the end of 2006 , and almost $8.7 \%$ points lower at the end of 2011. Most of these complementarities arise from bundling fixed-line and broadband in a single contract (enabling price discounts and convenience). These findings show that the fixed-line incumbent has not only been able to leverage its advantage to mobile voice services, but more importantly also to broadband.

There is a growing body of literature on substitution between fixed-line and mobile services, as reviewed in the next section. However, none of this work systematically analyzes this sub- 
stitution with detailed household-level data to account for heterogeneity in substitution across households and regions. Furthermore, no work has investigated how complementarities have slowed down fixed-to-mobile substitution, through incumbency advantages and synergies with fixed broadband.

The remainder of the article is organized as follows. Section 2 discusses the relevant literature. Section 3 discusses the data used in the estimation. Section 4 introduces the econometric framework. Section 5 presents the estimation results. Finally, Section 6 concludes.

\section{Literature Review}

There is a growing body of literature on substitution between fixed-line and mobile services, which was recently reviewed in Vogelsang (2010). Most of these studies use cross-country or country-level aggregate data and find substitution between fixed-line and mobile telecommunications services (see Gruber and Verboven (2001), Ward and Zheng (2012), Grzybowski (2014)).

A number of other studies rely on consumer-level data. Rodini et al. (2003) estimate the substitutability between fixed-line and mobile access using data on U.S. households and binary logit model. They find that second fixed line and mobile services are substitutes for one another. In another paper, Ward and Woroch (2010) use quarterly survey panel data in the U.S. for years 1999-2001 and a difference-in-difference analysis to estimate own- and cross-price elasticities of demand for fixed and mobile services, and they find moderate substitution between these two. García-Marinoso and Suarez (2013) use Spanish household panel data for the years 2004-2009 to analyze substitution from fixed to mobile services. They find that apart from household characteristics also the availability of internet and mobile services plays a role, while prices and expenditures have no, or a small, impact on the substitution decision.

Among papers which focus on internet access, Cardona et al. (2009) use household survey data for Austria to estimate discrete choice models and find that cable modem and mobile access are close substitutes to DSL and that they are in the same market as DSL. Srinuan et al. (2012) use discrete choice model on survey data for Sweden and find that mobile broadband and fixed broadband technologies are close substitutes when they are locally available. Grzybowski et al (2013) estimate a mixed logit model using survey data for Slovakia and find that mobile broadband should be included in the relevant market for internet access based on fixed broadband 
technologies. However, none of these studies relate internet access to the demand of fixed or mobile connections in voice services.

The studies mentioned above which use discrete choice framework essentially assume some degree of substitution between telecommunications technologies. There are only two recent studies, Liu et al. (2010) and Macher et al. (2011), which explicitly model the possibility of substitution or complementarity between telecommunications technologies in a discrete choice framework. In the first paper, Liu et al. (2010) use a panel survey data of U.S. households for years 2004-2006 to estimate a discrete choice model for broadband services. Their model allows also for parallel choices of related services such as cable TV and local phone and for state-dependence in provider choices. They find evidence of strong complementarities between the consumption of broadband, cable TV and local phone services, where the main source of complementarities are the benefits derived by consumers from having a single provider for multiple services. In the second paper, Macher et al. (2012) estimate a bivariate probit model using U.S. household data for years 2003-2010 to analyze whether fixed-line and mobile connections are substitutes or complements. Using the estimates of cross-price effects they conclude that mobile and fixed-line connections are substitutes rather than complements.

Our approach follows Gentzkow (2007) but in addition we also consider heterogeneity in substitution across households and across the many geographic regions within the 27 EU countries. ${ }^{2}$ This allow us to conclude whether fixed-line and mobile connections are substitutes, complements or independent from each other in a particular country. We then comment on the hypothesis that consumers across the EU differ in the perception of fixed-line and mobile services and to what extent this is driven by population characteristics. We also analyze whether there is any incumbency advantages in offering to consumers both fixed-line and mobile services and to what extent the use of internet technologies influences substitution or complementarity between mobile and fixed-line connections.

\footnotetext{
${ }^{2}$ Gentzkow (2007) also reports estimating a model specification in which the substitution parameter $\Gamma$ varies with observable consumer characteristics.
} 


\section{Data}

Survey data We use six Special Eurobarometer surveys conducted in 27 EU countries by the TNS Opinion \& Social Network on behalf of the European Commission. The surveys were conducted in intervals of approximately 12 months between December 2005 and December 2011, with the exception of the year $2008 .^{3}$ The purpose of the surveys is to follow trends in electronic communications markets and to assess how EU households and citizens derive benefits from increasingly competitive and innovative digital environment. ${ }^{4}$ A description of the sampling methodology and a summary of the results for questions related to telecommunications services can be found in the Eurobarometer reports published on the website of the Commission. The survey should be representative on a country level. The Commission is granting access to Eurobarometer primary data for re-use in social science research and training. We have processed and combined these six surveys and selected variables which are relevant for our questions of interest. Table 1 provides a list of variables which we use in the estimation. Table B.1 in the Appendix shows the number of observations used in the analysis for each country. Tables B.2, B.3 and B.4 in the Appendix illustrate trends in the data with respect to the usage of fixed-line and mobile connections.

Prices Data on prices of mobile and fixed-line telecommunications services comes from the reports on "Telecoms Price Developments" produced on annual basis by the consultancy firm

\footnotetext{
${ }^{3}$ There are two 2011 surveys. The first one was conducted in February-March 2011 and the second one was conducted in December 2011. The results of the first survey should not be much different if it was conducted at the end of 2010 instead. We consider therefore that it is equivalent to 2010 survey for consistency with other surveys which were conducted at the end of each year.

${ }^{4}$ The surveys used in the analysis are: (i) Eurobarometer 64.4: Mental Well-Being, Telecommunications, Harmful internet Content, and Farm Animal Welfare, December 2005 - January 2006; (ii) Eurobarometer 66.3: Social Reality, E-Communications, Commin Agricultural Policy, Discrimination and the Media, and Medical Research, November - December 2006; (iii) Eurobarometer 68.2: European Union Policy and Decision Making, Corruption, Civil Justice, E-Communications, Agriculture, and Environmental Protection, November - December 2007; (iv) Eurobarometer 72.5: E-Communications, Agriculture, Geographical and Labor Market Mobility, and Knowledge of Antibiotic Use, November-December 2009; (v) Eurobarometer 75.1: Energy in the European Union, Citizens' Rights, E-Communications, the Internal Market, and Carbon Dioxide Capture and Storage, FebruaryMarch 2011; (vi) Special Eurobarometer 381: E-communications Household Survey, December 2011.
} 
Teligen on behalf of the European Commission's Directorate General for Information Society. The objective of these reports is to analyze price developments in the Member States of the European Union in years 1998-2010. The reports show prices as of 1st August each year from 1998 to 2004, as of 1st September from 2005 to 2007, and as of 15th September from 2008 to 2010. Teligen collected tariff data directly from the websites and price-lists of telecoms operators. According to Teligen tariffs data were validated by the NRAs to ensure the reliability of information. We miss Eurobarometer data for year 2008 because the survey was not conducted in this year. ${ }^{5}$ There is no pricing data available for 2011, for which we have the last wave of the survey. We therefore assume that prices were the same in 2010 and $2011 .^{6}$

Prices used in this study are so called OECD composite baskets for fixed-line and mobile services. Due to changes in the usage patterns over time the definitions of the OECD baskets were updated in the following years: 2002, 2006 and 2010. The price indices used in this paper are based the 2002 OECD basket definition. There are three usage profiles considered when constructing price indices for mobile services: low, medium and high. In the paper we use low usage profile which is constructed using 30 text messages and 25 outgoing calls (37 minutes) per month, where $42 \%$ of calls are to fixed line phones and $58 \%$ to mobile phones. Mobile baskets are reported for the representative tariffs from two network operators with the greatest number of subscribers in each country. Price indices for fixed-line services are based on the 2000 OECD basket definition including per month 100 national calls, 6 international calls and 10 calls to mobile numbers. Fixed charges are also included in the basket with the appropriate annual rental charge, and with the installation charge depreciated over 5 years. The distribution and duration of calls is detailed in Teligen's reports, which are publicly available on the website of the

\footnotetext{
${ }^{5}$ We have combined the Teligen pricing data with the Eurobarometer survey data. Teligen data for years 2005-2010 was collected in September, which is a few months earlier than the Eurobarometer data, which was usually collected at the end of the year. We assume that Eurobarometer data with fieldwork in: December 2005 - January 2006 relates to 2005 Teligen data; November-December 2006 relates to 2006; November 2007 January 2008 relates to 2007; November-December 2009 relates to 2009; February-March 2011 relates to 2010 and December 2011 also relates to 2010 due to lack of 2011 price information.

${ }^{6}$ The prices for mobile services in years 2005-2010 decreased on average by $33 \%$ with large differences across countries. The average change in prices between 2009 and 2010 is $0 \%$. Therefore, it seems reasonable to assume that price in 2011 remained the same as in 2010. Using prices imputed in a different way should have only a marginal impact on the estimates.
} 
European Commission. For fixed-line services, Teligen provides only baskets for the incumbent operator in each country. There is no pricing information available for broadband services. We explain how prices are constructed for each estimation when introducing the models.

Regional data We lack individual-level information on income, which is approximated using regional GDP per capita statistics from Eurostat on so called NUTS 2 level. NUTS is a geocode standard for referencing the administrative divisions of the EU countries for statistical purposes. There are three NUTS levels. We use data at the NUTS 2 level, which refers to basic regions with population ranging between 800 thousands and 3 million inhabitants. ${ }^{7}$ There are 273 NUTS 2 regions in $27 \mathrm{EU}$ countries used in the analysis. The survey includes information on the NUTS 2 region in which households live that is combined with Eurostat statistics. We also use NUTS 2 level information to define regional availability of broadband technologies as discussed below.

\section{Econometric Model}

We model the households' decisions whether to use fixed-line and/or voice mobile telephone services, and, in an extension, the use of voice services in combination with the decision to use a particular internet technology. A standard discrete choice framework is not suitable for such analysis because households may simultaneously choose more than one alternative: (i) they may use both fixed and mobile voice services, and (ii) these services can be combined with a certain internet technology. To incorporate the possibility that households may choose multiple options, we follow the approach of Gentzkow (2007) and formulate a discrete choice model for bundles of alternatives. His model is designed to handle bivariate choice such as decision problem (i) and may not extend to a greater number of choice alternatives, as in the case of (ii). Nevertheless, as discussed in Section 5 below, both models lead to analogous conclusion with respect to the substitution between fixed-line and mobile connections.

We first present the base model, where households choose only between voice services (section 4.1), and then extend the model to incorporate the simultaneous choice of internet technology (section 4.2).

\footnotetext{
${ }^{7}$ Source:http://epp.eurostat.ec.europa.eu/portal/page/portal/nuts_nomenclature/introduction
} 


\subsection{Demand for voice services}

Base model A household $i$ has available two possible voice services, indexed by $j$ : fixed-line $(j=F)$ and mobile $(j=M)$. The choice set consists of the four possible bundles of these services, $r \in\{0, F, M, F+M\}$, where $r=0$ refers to the choice of no telephone at all, and $r=F+M$ refers to the choice of both fixed and mobile services. Figure 1 shows the shares of these four choice alternatives across 27 EU countries in March 2011. Table 2 summarizes these shares for all the countries, showing that the majority of households in the sample have both a fixed and a mobile voice connection, many households either have a fixed or a mobile voice line, while the minority has no voice connection at all.

Household $i$ 's stand-alone utility from a connection to voice service $j$ is:

$$
\bar{u}_{i j}=x_{i} \beta_{j}+\alpha p_{i j}
$$

where $p_{i j}$ is the price paid by individual $i$ for voice service $j$ and $x_{i}$ is a vector of household characteristics influencing the utility of the voice service. The price $p_{i j}$ refers to the fixed subscription charge plus the usage cost of a representative consumer. For the price of fixed-line we use the cost of usage basket of the incumbent's tariff, and for the price of mobile we use an average of the costs of two usage baskets: one for incumbent's tariff and one for a tariff of the main competitor in terms of market shares. Fixed-line prices are the same for all households on the country-level varying over time. Mobile prices are also the same on the country-level varying over time, but they differ across households depending on whether they declared using a prepaid or post-paid tariff. The vector of household characteristics $x_{i}$ consists of three groups of variables: household demographics (such as sex, age, education, household size); employment status (such as student, retired or employment sector); and regional and time information (such as country, regional GDP per capita, time effects).

A household's utility for a bundle of voice services $r \in\{0, F, M, F+M\}$ is:

$$
\begin{array}{ll}
u_{i r}=\varepsilon_{i r} & \text { if } r=0 \\
u_{i r}=\sum_{j \in r} \bar{u}_{i j}+\Gamma_{i r}+\varepsilon_{i r}, & \text { if } r \neq 0
\end{array}
$$

where $j \in r$ denotes the set of products indexed by $j$ which are included in bundle $r$. The term $\Gamma_{i r}$ is the difference between the household's total utility for the bundle $r$ and the sum 
of the stand-alone utilities $\bar{u}_{i j}$ for the services $j \in r$. For the singleton bundles, $r=F$ and $r=M$, we set $\Gamma_{i r}=0$. For the real bundle $r=F+M$, the services are complements if $\Gamma_{i r}>0$, substitutes if $\Gamma_{i r}<0$, and independent if $\Gamma_{i r}=0$. Gentzkow (2007) provides a discussion how price affects the marginal consumers in these three situations. We specify $\Gamma_{i r}=x_{i} \gamma$, which allows for household heterogeneity in their valuation of the substitutability or complementarity of fixed and mobile services. The heterogeneity depends on the same household characteristics that affect the stand-alone utilities for fixed and mobile voice (demographics, employment status and regional and time information). The terms $\varepsilon_{i r}$ are i.i.d. type I extreme value distributed, i.e., the typical "logit" error terms.

Based on this specification, we obtain the following utilities for the four bundles

$$
\begin{aligned}
u_{i 0} & =\varepsilon_{i 0} \\
u_{i F} & =x_{i} \beta_{F}+\alpha p_{i F}+\varepsilon_{i F} \\
u_{i M} & =x_{i} \beta_{M}+\alpha p_{i M}+\varepsilon_{i M} \\
u_{i F+M} & =x_{i}\left(\beta_{F}+\beta_{M}+\gamma\right)+\alpha\left(p_{i F}+p_{i M}\right)+\varepsilon_{i F+M} .
\end{aligned}
$$

Note that we only observe prices for the unbundled voice services, $p_{i F}$ and $p_{i M}$, and define the price of a bundled service as $p_{i F+M}=p_{i F}+p_{i M}$. If a household adopts both fixed and mobile from a different operator, as long as usage remains unchanged, this sum is an accurate description of the cost. ${ }^{8}$ If, however, a household has a contract bundle for fixed and mobile voice from the same operator, then the household may pay a lower price because of a discount or receive some other contractual benefits. To account for this "contractual complementarity", we make use of information in the survey and construct a dummy variable equal to 1 if the household has a contract bundle for fixed and mobile voice from the same operator, and 0 if it adopts fixed and mobile voice from a different operator. Our estimate of the parameter $\gamma$ may then be viewed as the extent of substitution/complementarity between fixed and mobile net of the contractual complementarity that arises from the fact that a household makes use of a bundled contract.

Incumbent versus competitor We can easily extend this framework to distinguish between the type of operator providing the voice service: incumbent or competitor. Due to lack of

\footnotetext{
${ }^{8}$ The usage of fixed-line and mobile telephones may obviously change when both services are used together.
} 
detailed data all non-incumbent operators are denoted as competitor. The index $j$ now refers to voice service and operator type: incumbent fixed-line $\left(j=F_{1}\right)$, competitor fixed-line $\left(j=F_{2}\right)$, incumbent mobile $\left(j=M_{1}\right)$, competitor mobile $\left(j=M_{2}\right)$. The choice set then consists of nine possible bundles $r \in\left\{0, F_{1}, F_{2}, M_{1}, M_{2}, F_{1}+M_{1}, F_{1}+M_{2}, F_{2}+M_{1}, F_{2}+M_{2}\right\}$. The utilities for the stand-alone alternatives $j$ and for the bundles $r$ take the same form as before. Since there is a large number of bundles we will impose restrictions on the number of interaction terms, as explained in the section discussing estimation results.

The information on the name of operator used by the household is only available for 2005 and 2006, so we limit this analysis to these first two years of the survey. Table 3 shows that most households have a fixed-line connection from the incumbent, and among these households roughly equal numbers have a mobile connection from the incumbent and from a competitor. The number of households with a fixed-line connection from a competitor is smaller and in some countries fixed-line services are provided exclusively by the incumbent. In the UK, on the other hand, the incumbent does not operate mobile services at all.

Due to limited price information we have to make the following assumptions. For fixed-line we only have the cost of usage basket for a representative tariff of the incumbent operator. We assume therefore that competitors' fixed-line prices are exactly the same as of the incumbent. For mobile services we have the cost of usage basket for a representative tariff of the incumbent and of the main competitor in terms of market share. We assume that mobile prices are the same of all the non-incumbent operators. Hence, as in our base model fixed-line prices are the same for all households on the country-level varying over time. Mobile prices are also on the country-level varying over time but differ between incumbent and competitor and across households depending on whether they declared using prepaid or post-paid tariff.

\subsection{Demand for voice services and internet technology}

We now extend the framework to incorporate the households' choice of internet technology. Each household has available two voice services $j=\{F, M\}$ (as in the base model) and six possible internet technology choices: (i) no internet, (ii) copper-based dial-up, or "narrowband"; (iii) copper-based DSL broadband; (iv) cable modem broadband; (v) mobile broadband; and (vi) other broadband (usually fibre or WiFi). We denote these internet options by $k=0,1, \cdots, 5$. 
Therefore, the households' choice set consists of a maximum of 24 possible bundles of services: the 4 voice bundles $\{0, F, M, F+M\}$ times the 6 internet choices. In practice, however, there are almost no households without a voice service who have an internet connection via any of the 5 technologies, as shown in Table 4 . We therefore restrict the choice set to the remaining 19 alternatives and drop from the analysis the small number of households who selected any of these 5 alternatives which are not considered as viable in our analysis. Note that in principle households may choose more than one internet technology. However, as shown in Table 5, the incidence of having more than one internet technology is rare, and we remove these households from the analysis. In most of these cases, people have both fixed and mobile broadband.

A household's stand-alone utility for voice service $j$ is the same as specified earlier in (1). The additional utility from combining fixed and mobile technology, $r=F+M$, is also specified earlier as $\Gamma_{i r}=x_{i} \gamma$, where: if $\Gamma_{i r}>0$ fixed and mobile are complements; they are substitutes if $\Gamma_{i r}<0$; and they are independent if $\Gamma_{i r}=0$. The stand-alone utility for an internet technology $k$ is not identified because in the sample households always combine internet with at least one voice service. The household's valuation of a specific internet technology $k$ may depend on the type of voice service $j \in\{F, M\}$, reflecting substitution or complementarity between a particular voice services and internet. For example, households may keep a copper fixed-line connection for voice because it may also be used to access internet via dial-up or DSL. Conversely, households may give up their fixed-line connection for voice services when they access internet via a cable modem, a mobile modem or fibre. ${ }^{9}$ To model this, we let $\Delta_{i j, k}$ to represent the additional utility from adopting internet technology $k$ when the household has adopted the voice service $j \in\{F, M\}$. We specify $\Delta_{i j, k}=\delta_{j, k}+x_{i} \delta_{k}$. The first term $\delta_{j, k}$ is a fixed effect capturing the valuations for combining the voice service $j$ with the various internet technologies $k$. The second term captures the effects of household characteristics on the valuation of internet connection $k$. For example, $\Delta_{i F, 1}$ is the additional utility from adopting copper-based dial-up $(k=1)$ when the household has a fixed-line. To simplify, we assume that $\delta_{k}$ is the same for all internet connections $k>0$ and denote $\delta_{k}=\delta_{I}$ for $k>0$. Hence, $\delta_{I}$ captures households' valuations for

\footnotetext{
${ }^{9}$ Grzybowski (2013) uses the aggregate data from the Eurobarometer reports published by the European Commission to analyze fixed-to-mobile substitution. He reports that the share of 'fixed + mobile' households is positively correlated with percentage of households having internet access and negatively correlated with the share of households having cable modem.
} 
any internet connection. The intercepts $\delta_{j, k}$ are still internet technology-specific.

A household's utility for a voice service $r \in\{0, F, M, F+M\}$ in combination with an internet technology $k$ can then be specified as:

$$
\begin{array}{ll}
u_{i r, k}=\varepsilon_{i r, k} & \text { if } r=0, k=0 \\
u_{i r, k}=\sum_{j \in r} \bar{u}_{i j}+\Gamma_{i r}+\Delta_{i j, k}+\varepsilon_{i r, k} & \text { if } r \neq 0,
\end{array}
$$

where the terms $\varepsilon_{i r, k}$ are again the logit error terms.

This gives the following utilities

$$
\begin{aligned}
u_{i 0,0} & =\varepsilon_{i 0,0} \\
u_{i F, k} & =x_{i}\left(\beta_{F}+\delta_{I}\right)+\delta_{F, k}+\alpha p_{i F}+\varepsilon_{i F, k} \\
u_{i M, k} & =x_{i}\left(\beta_{M}+\delta_{I}\right)+\delta_{M, k}+\alpha p_{i M}+\varepsilon_{i M, k} \\
u_{i F+M, k} & =x_{i}\left(\beta_{F}+\beta_{M}+\gamma+\delta_{I}\right)+\left(\delta_{F, k}+\delta_{M, k}\right)+\alpha\left(p_{i F}+p_{i M}\right)+\varepsilon_{i F+M, k} .
\end{aligned}
$$

\subsection{Choice Probabilities and Estimation}

In the first model households choose the voice bundle $r$ and in the second model they simultaneously choose the voice bundle $r$ and internet technology $k$ that maximizes random utility. We focus here on the second model which is more general. Given that the $\varepsilon_{i r, k}$ are type I extreme value distributed, random utility maximization results in the following logit choice probabilities:

$$
s_{i r, k}=\frac{\exp \left(V_{i r, k}\right)}{1+\sum_{k} \sum_{r} \exp \left(V_{i r, k}\right)}
$$

where $V_{i r, k} \equiv u_{i r, k}-\varepsilon_{i r, k}$ is the deterministic component of household $i$ 's utility for voice bundle $r$ and internet technology $k .^{10}$

Both in the first model (voice bundles only) and in the second model (voice bundles + internet), we take into account the geographic availability of the choice alternatives. First, while mobile voice services are universally available in all the EU countries, fixed voice services may not always be available in rural areas, especially in the CEE countries. As a sensitivity check, we estimate the models on a sub-sample of households living in large towns and cities, where

\footnotetext{
${ }^{10}$ We can also consider an alternative model specification, in which consumers choose between prepaid and postpaid mobile services. However, such analysis would be limited to years 2008, 2010 and 2011 only, for which we have prices for both prepaid and postpaid.
} 
fixed-line connection should be in general available. The estimation results are broadly similar. Hence, we estimate the final model assuming that fixed-line is available to all households in each country.

Second, certain types of broadband internet technologies may not be available in certain geographic areas or even in the whole country. In the second model, we therefore restrict the choice sets to those broadband technologies which are available in the region where the household resides, where the residence information is specified by NUTS 2 area, which is explained in Section 3. We construct the choice set of broadband technologies as follows. If there is at least one household in the survey which uses a particular broadband technology in a given NUTS 2 area, we assume that it is also available to all other households in this area. This assumption still makes the choice set potentially too broad, because the fact that there are households using a particular broadband technology in a given geographic area does not imply that it is available to all other households in this area.

The choice probabilities (with suitably modified summations in the numerator of (2) to account for limited geographic availability of broadband) form the basis of the likelihood function which is taken to the data. Defining $y_{i r, k}=1$ if household $i$ selects voice bundle $r$ and internet technology $k$, and $y_{i j, k}=0$ otherwise, the log likelihood function can be written as:

$$
\mathcal{L}(\theta)=\sum_{i}^{N} \sum_{r, k} y_{i r, k} \log s_{i r, k}(\theta) .
$$

where $\theta$ is the vector of all parameters to be estimated. The maximum likelihood estimator is the value of the parameter vector $\theta$ that maximizes (3). The model allows for rich substitution patterns because of a large set of included observed household characteristics.

We have estimated a model in which we allow for the correlation between bivariate choices due to unobserved preferences as in Gentzkow (2007), using a random coefficients model. The results indicate that to a large extent we are able to control for the correlation of fixed-line and mobile choices by means of observable individual characteristics. While the unobserved correlation parameter is significant in the model without individual characteristics, it becomes insignificant in the model with a detailed set of individual characteristics. We therefore focus on the base model with only observed heterogeneity in the discussion of the estimation results and counterfactual simulations. We present the derivation of the random coefficients model and 
the estimation results in Appendix. ${ }^{11}$

\section{Empirical Results}

In section 5.1 we present the empirical results for the two models where households only choose between voice services (Tables 6 and 7). Section 5.2 then considers the results from the third model, where households simultaneously choose the voice service and the internet technology, if any (Table 9). In all three specifications, we include a rich set of household characteristics. Summary statistics for these household characteristics are shown earlier in Table 1.

\section{$5.1 \quad$ Voice services}

Table 6 shows the empirical results for the two models where households only choose between the two voice services. The left part considers the base model, where the choice set is limited to 4 alternatives: $\{0, F, M, F+M\}$, i.e. households may either choose no telephone, fixed, mobile or both. The right part considers the second model with an extended choice set of 9 alternatives, $\left\{0, F_{1}, F_{2}, M_{1}, M_{2}, F_{1}+M_{1}, F_{1}+M_{2}, F_{2}+M_{1}, F_{2}+M_{2}\right\}$. As discussed above, in this model households also decide whether to take fixed or mobile services from the incumbent (fixed-line) operator (subscript 1), or from a competitor (subscript 2).

In both specifications, price has a negative and highly significant effect on utility. ${ }^{12}$ In addition to the price parameter, Table 6 reports three columns: the first and second columns give the stand-alone utilities for fixed-line and mobile voice services $\left(\beta_{F}\right.$ and $\left.\beta_{M}\right)$, and the third column shows the substitution or complementarity effects between fixed and mobile $(\gamma)$. Table 6 presents only the main effects and the interactions with regional variables (regional income per capita and a dummy variable for the group of CEE countries), while Table 7 shows

\footnotetext{
${ }^{11}$ Arora (1996) and Miravete and Pernias (2010) argue that it is not possible conclude on complementarity (substitutability from the positive (negative) correlation in choices due to indirect effects. Even though these papers consider models without prices, the same identification issue is likely to persist when, as in our paper, fixed-line and mobile prices are included in the estimation. We thank the referee for indicating this problem to us.

${ }^{12}$ We have checked for the robustness of estimates with respect to the price index for mobile services which we use in the estimation. We have re-estimated the model using an average price for low, medium and high usage baskets instead of the low usage basket. The price coefficient remains significant and almost unchanged.
} 
the interactions with the household characteristics for the first specification. The estimated household interactions for the second model (and our subsequent third model with simultaneous choice of broadband) are very similar, so we only present them in the Appendix.

We focus most of our discussion on the estimated substitution effects (parameter vector $\gamma$ ), but also briefly comment on the stand-alone effects $\left(\beta_{F}\right.$ and $\left.\beta_{M}\right)$.

Base model According to the left part of Table 6, households who live in richer regions are more likely to have both mobile and fixed-line connections (positive and strongly significant $\beta_{F}$ and $\left.\beta_{M}\right)$. We compute the marginal effect of income on the probability of having a fixedline connection, which on average in the sample is 0.22 . It is a bit higher than the average marginal effect on the probability of having a mobile connection of 0.14 . Hence, a $1 \%$ increase in income increases fixed-line connections by $0.22 \%$ and mobile connections by $0.14 \%$. Furthermore, households from the CEE countries are more likely to have mobile, but less likely to have fixedline connections than households from the WE countries (after controlling for regional income and other household characteristics). Finally, the adoption of mobile phones is still increasing over time (during 2006-2011), whereas the adoption of fixed-line services shows limited variation across years.

Our main interest is in the parameter vector $\gamma$, which measures the extent of substitution (or potentially complementarity) between fixed and mobile voice. Notice first that the intercept in $\gamma$ is negative and highly significant. This estimate implies that households on average tend to view fixed-line and mobile voice as substitutes. Furthermore, the extent of substitution became considerably stronger in the more recent years 2009-2011, compared with the early years of our study 2006-2008. To assess this further, we computed the average "fixed-to-mobile" diversion ratio implied by our base model estimates. This ratio is the reduction in fixed-line households relative to the increase in mobile households after a price drop for mobile voice services. ${ }^{13}$ The average fixed-to-mobile diversion ratio was 9.0\% during 2006-2008, and it increased to $15.6 \%$ during 2009-2011. This means that, in 2009-2011, a sizeable $15.6 \%$ of the (marginal) mobile

\footnotetext{
${ }^{13}$ Formally, this diversion ratio is $\left(\sum_{k} \partial\left(s_{i F, k}+s_{i M+F, k}\right) / \partial p_{i M}\right) /\left(\sum_{k} \partial\left(s_{i M, k}+s_{i M+F, k}\right) / \partial p_{i M}\right)$, which for the base model specification without broadband yields $\left(\left(s_{i F}+s_{i M+F}\right)\left(s_{i M}+s_{i M+F}\right)-s_{i M+F}\right) /\left(\left(s_{i M}+s_{i M+F}\right)(1-\right.$ $\left.s_{i M}-s_{i M+F}\right)$ ). We compute the diversion ratios from expression (2) using the parameter estimates for the base model, and averaging the values over households.
} 
households would otherwise have chosen fixed-line access.

We have also estimated the sample average own- and cross-price elasticities implied by our base model estimates using Petrin-Train control function approach, for which the standard logit formulas had to be adapted accordingly. The average own price elasticity for fixed-line connections -0.43 and for mobile is -0.21 , as shown in Table 8 . The average cross-price elasticities are $0.021 .{ }^{14}$

One can also observe interesting differences in substitution across regions. There is a stronger substitution in the areas with a high regional income per capita and in the CEE countries (negative and significant effect in $\gamma$ ). The stronger substitution in the CEE countries (after controlling for regional income and differences in household characteristics) may be due to the lower quality of the fixed network than in the WE countries. ${ }^{15}$ Furthermore, there is a substantial heterogeneity across households in the perceived substitutability between fixed-line and mobile services, as shown in Table 7. For example, households who live in cities, males and highly educated people are more likely to substitute to mobile, while large households and households with many kids are less likely to substitute. Proprietors and travelling professions consider fixed-line and mobile as stronger substitutes, and households with non-working, housekeeping members tend to view fixed-line and mobile as complementary. ${ }^{16}$

\footnotetext{
${ }^{14}$ Our estimates are comparable to the price elasticities reported by the New Zealand Commerce Commission (2003), which summarizes estimation results for international studies. For instance, price elasticities for mobile subscription are reported to fall in the range between -0.06 and -0.54. In another paper, Doganoglu and Grzybowski (2007) estimate a nested logit model and report price elasticities of demand for mobile subscriptions in Germany ranging between -0.19 and -0.52 .

${ }^{15}$ As mentioned earlier, the model was also estimated for a limited sample of households which live in towns and cities to account for possible lack of availability of fixed-line in rural areas, but the results were broadly similar. In another specification, we considered a set of dummy variables for all the countries instead of the CEE dummy. There are significant differences in the estimates of dummy variables across countries, with the greatest negative values for the CEE countries. The remaining estimates are very similar.

${ }^{16}$ Table 7 shows the effects of household characteristics on the stand-alone utilities for fixed-line and mobile voice services $\left(\beta_{F}\right.$ and $\left.\beta_{M}\right)$. City households have a higher valuation for both fixed-line and mobile voice services than households in smaller towns and rural areas. The same is true for married households, for larger households with a small number of kids below age 15, and for more educated households. Males and younger households also have a higher valuation for mobile phones, but they have a lower valuation for a fixed-line connection. There are also significant differences in the stand-alone valuations for mobile and fixed-line across different professional groups.
} 
Finally, it is interesting to consider the estimated coefficient for the contract bundle variable. This is significant and positive, which means that consumers benefit from contractual complementarities when they have a single contract for fixed and mobile voice at the same operator. Such complementarities may be present because of price discounts or because of convenience or some other contractual advantages. We discuss this further in the next subsection, where we distinguish between incumbents and competitors.

Incumbent versus competitor The right part of Table 6 shows the estimation results for the second model with the expanded choice set, which makes a distinction between having a fixed-line or mobile connection from the incumbent or a competitor. This model uses data for years 2005 and 2006, because information about the operator used by the households is available for these years only. The impact of household characteristics is similar to the previous model (shown in Table 7), so we only present these results in the Appendix. Substitution between fixed and mobile is weaker, which is mainly because we consider years 2005 and 2006.

Our new findings relate to the role of the incumbency status. Not surprisingly, households have a considerably higher valuation for a fixed-line connection at the incumbent fixed-line operator (second column). This simply reflects the fact that the incumbent operator is the dominant provider of fixed-line services and owns most of the fixed telephony network, to which competitors need to obtain access. Furthermore, households tend to have a lower valuation for a mobile connection that is offered by the incumbent (first column). This reflects the fact that most European countries have strongly promoted competition in the mobile telecommunications market through the policy of granting licences to develop mobile networks. Even though the incumbent was typically granted a mobile licence early on, the competitors altogether tend to have greater market share than the incumbent.

Most interestingly, we can now distinguish between two sources of complementarity: contractual complementarity from having a single contract for fixed and mobile at the same operator (as before) and the complementarity between the incumbent's fixed and mobile network (third column). First, the contractual complementarity is still estimated to be positive and highly significant, but it is lower than in the base model. Second, the complementarity between the incumbent's fixed-line and mobile voice services is also highly significant. In this sense, we can 
conclude that the incumbent fixed-line operators have an intrinsic advantage in the mobile market. They benefit not only from the possibility of offering bundled contracts (as the entrants can do as well), but also from additional advantages relative to entrants. The fixed-line incumbents which have a dominant position in fixed telephony in almost all of the EU countries thus have the possibility to leverage this position into the mobile telephony market.

To summarize, the results from the base model and its extension establish that fixed-line connections are in decline because of significant substitution from fixed to mobile telephony. But the decline has been slowed down because of various complementarities: bundled contracts and incumbency advantages when fixed-line incumbents are also active in mobile telephony. To quantify the importance of these findings, we performed several policy counterfactuals to assess the impact of the introduction of mobile voice services.

Counterfactuals: the impact of mobile on fixed-line and mobile penetration Table 10 shows the impact of the mobile telephony on fixed-line and mobile penetration in the EU. For the year 2011 the estimated impact is based on the first model (base model in left part of Table 6). For the year 2006 the estimated impact is based on the second model (extended base model in right part of Table 6), since for this year we observe whether a household has a voice connection from the incumbent or a competitor.

The first row in Table 10 shows the penetration rates of fixed-line, mobile, fixed-line plus mobile and no voice adoption, as predicted by the model under the status quo in 2006 and $2011 .{ }^{17}$ The second row shows the impact of removing mobile voice services, implemented as a prohibitive (or "infinite") price increase for mobile voice. ${ }^{18}$ A comparison of both rows shows the following. In 2006 mobile telephony reduced the fixed-line penetration rate by $5.9 \%$ points $(66.9 \%$, versus $72.8 \%$ if mobile telephony had not existed). In 2011 the impact was even stronger: mobile telephony reduced fixed-line penetration by $14.1 \%$ points $(63.1 \%$, versus $77.3 \%$ without mobile telephony). These numbers are consistent with our earlier reported fixed-to-mobile diversion ratios. ${ }^{19}$ While mobile telephony was detrimental for the fixed-line network, it also implied a

\footnotetext{
${ }^{17}$ The predicted penetration rates are very close to the actual penetration rate, indicating a good model fit.

${ }^{18}$ Removing mobile phones completely is not realistic but it can be used for comparison with the other counterfactual scenarios.

${ }^{19}$ The fixed-to-mobile diversion ratio is $7.7 \%$ in $2006(=0.729-0.669) / 0.78$, and $15.6 \%$ in $2011(=0.772-0.632) / 0.9$.
} 
much larger number of households with voice access. For example, only $2.4 \%$ of the households have no telephony at the end of 2011, and this would have been $22.7 \%$ if there had not been mobile telephony (mainly in poorer regions).

The third row shows a case in which prices of mobile services remain unchanged since 2005 . The purpose of this counterfactual simulation is to consider a potential impact of regulation on fixed-to-mobile substitution. In general, prices of mobile service tend to decrease over time, which may be partly due to regulation of interconnection charges. For instance, as reported by the Body of European Regulators of Electronic Communications (BEREC), the average mobile termination charges in the EU decreased from 12.81 cents in 2007 to 3.95 cents in 2012, which is $69 \%$. The prices of mobile services which we use in this analysis decreased on average by $17 \%$ in 2006 and by $33 \%$ in 2011 , as compared to 2005 , but with a large variation in price changes across countries. If we attribute the decline in prices of mobile services to regulation of interconnection charges, this counterfactual simulation may be considered as an approximation of the impact of regulation on the fixed-to-mobile substitution. The third row indicates that there are only marginal changes in mobile and fixed-line penetration levels relative to the status quo. In 2006 mobile penetration would be $77.8 \%$ versus $77.9 \%$ in the status quo and in 2011 it would be $88.5 \%$ versus $89.9 \%$ in the status quo. Fixed-line penetration would remain unchanged in 2006 at $66.9 \%$ and would be marginally higher in 2011 at $63.3 \%$, as compared to $63.1 \%$ in the status quo. Hence, regulation of interconnection charges and corresponding decline in retail prices has negligible impact on fixed-to-mobile substitution.

The fourth row shows the impact of bundled contracts, implemented by assuming households have no advantage from bundling mobile and fixed-line services in a single contract (as we estimated in Table 6). In 2006 contractual bundling increased the fixed-line network by $0.5 \%$ points (from $66.4 \%$ to $66.9 \%$ ). In 2011, the impact of bundling increased the fixed-line network by $1.2 \%$ (from $61.9 \%$ to $63.1 \%$ ), which is due to greater use of bundling practices.

Finally, the fifth row shows the impact of the incumbent's advantage when it offers both fixed and mobile telephony, as has been allowed by regulators in most European countries. The possibility for the incumbent fixed operators to offer mobile had a positive impact on fixed-

They are of same order of magnitude as reported above, but not entirely comparable. Here, we consider a prohibitive price increase, the total effect (rather than the average), and for 2006 a different model specification. 
line penetration of $1.9 \%$ point (from $65.0 \%$ to $66.9 \%$ ). Furthermore, it also increases mobile penetration by $1 \%$ point (from $76.9 \%$ to $77.9 \%$ ). We also consider the impact of allowing the fixed incumbents to offer mobile on their market shares. The fixed incumbent obtains an additional $2.7 \%$ market share in fixed telephony when regulators allow it to also offer mobile (57.5\%-54.8\%). And it obtains an additional 5.4\% market share in mobile telephony (38.1\%$32.7 \%$ ), as compared to a mobile competitor that would not operate a fixed network.

In sum, the fixed-line operators thus benefit from two incumbency advantages when allowed to offer mobile: they protect their fixed-line market share, and can also leverage it in mobile telephony. Furthermore, these incumbency advantages do not hurt, but actually promote total fixed and mobile penetration.

\subsection{Voice services and internet technology}

Table 9 shows the empirical results for the third model, which considers the simultaneous choice of voice and internet technology. As discussed in Section 4, there are now 19 choice alternatives: the 4 voice bundles $\{0, F, M, F+M\}$, which may be combined with at most 6 possible internet choices (including no internet). In addition to the stand-alone utilities for voice $\left(\beta_{F}\right.$ and $\left.\beta_{M}\right)$ and substitution/complementarity effects between fixed and mobile $(\gamma)$, we now also estimate how household characteristics influence internet adoption $\left(\delta_{I}\right)$, and the substitution/complementary between fixed and mobile voice and the various internet technologies $\left(\delta_{j, k}\right)$. The estimates for the stand-alone utilities and substitution effects for voice services $\left(\beta_{F}, \beta_{M}\right.$ and $\left.\gamma\right)$ are comparable to our base model: mobile and fixed-line voice services are perceived as substitutes, and this is more so in the CEE countries than in the WE countries.

Our new findings relate to the substitution/complementarity effects between voice services and internet $\left(\delta_{j, k}\right)$. Based on Table 9, this can be summarized as follows. On the one hand, all five broadband technologies are complementary with a mobile voice connection, but the complementarity is strongest for the mobile broadband technology. On the other hand, DSL and dial-up are the only broadband technologies that show a strong complementarity with a fixed-line connection. Cable and other broadband show only very weak or no complementarity with a fixed-line connection, whereas mobile broadband is in fact a strong substitute for a fixed line connection. This follows from the fact that DSL and dial-up require households to have 
a copper line connection, so that they can obtain fixed-line voice services at small or no costs. In contrast, mobile broadband does not require a copper line connection, so that they become substitutes.

It is also interesting to note the complementarity which is generated from bundled contracts. As already found in the base model, a contract that bundles fixed and mobile voice generates complementarities (in the form of price discounts or convenience). Furthermore, there is an even stronger complementarity from contracts that bundle fixed voice with broadband internet (dialup or DSL). There is also some complementarity from bundling mobile voice with internet, but much weaker than for fixed voice.

Note that our model also includes interactions of household characteristics with internet access $\left(\delta_{I}\right)$. These results are shown in the Appendix, and we briefly review them here. First, households living in the cities and smaller towns are more likely to use internet, as compared to households from rural areas. Males and married households are more likely to have internet access. The same is true for larger households, households with many kids, younger and highly educated households.

To summarize, the results from the third model confirm the presence of significant substitution from fixed to mobile telephony. Furthermore, we find that the decline of fixed telephony has been slowed down because of the complementarity of the fixed network with different broadband technologies and the associated bundled contracts. As in the previous subsection, we now quantify the importance of these findings through several policy counterfactuals. We focus only on the impact of the introduction of internet. ${ }^{20}$

Counterfactuals: the impact of internet on fixed-line and mobile penetration Table 11 shows the impact of internet on fixed-line and mobile voice penetration in the EU. This is based on our third model 'base model + broadband' (for which the parameter estimates are reported in Table 9). The first row shows the predicted penetration rates under the status quo. These are close to the numbers in Table 10.

The second row shows the estimated impact of entirely removing internet. A comparison of

\footnotetext{
${ }^{20}$ The counterfactuals for the impact of mobile voice on fixed voice give similar results as in the two models in the previous section, so we do not report these here.
} 
the first and second row shows the following. Without the introduction of internet, fixed-line voice penetration would have been $7.1 \%$ points lower in $2006(69.1 \%-61.9 \%)$, and even $9.8 \%$ points lower in $2011(63.0 \%-53.2 \%)$. The complementarity with internet has thus been a main driver for slowing down the process of fixed-to-mobile substitution.

The third row of Table 11 shows how much of the broadband internet effect can be attributed to DSL, which is the main broadband technology in the EU requiring copper fixed-line connection. ${ }^{21}$ Without the DSL internet technology, fixed-line voice penetration would have been $6.3 \%$ points lower in 2006, and $8.7 \%$ points lower in 2011. Hence, most of the positive impact of internet on the fixed line network can be attributed to the complementarity with DSL.

Finally, the fourth row shows the impact of the contractual bundling practices on the fixed and mobile telephony networks. If fixed-line and internet were not offered as bundles, then fixed-line penetration would be up to $9.8 \%$ lower at the end of 2011 . Hence, the positive effect of internet on the fixed line network can be entirely attributed to the bundling practices. This can be in the form of price discounts or convenience from having a single provider for voice and internet.

The discussion focused so far on the large positive impact of internet on the fixed-line network. The impact of internet on the mobile network has also been positive but not surprisingly much smaller in magnitude. For example, without internet, mobile voice penetration in 2006 would have been $3.2 \%$ points lower $(79.0 \%-75.8 \%)$.

Tables 10 and 11 report predictions for the EU countries altogether, but there are significant differences across countries in how fixed-line penetration changes in these different scenarios. This is largely due to differences in substitution between fixed-line and mobile services and differences in the penetration of internet technologies.

The cross-country differences in fixed-to-mobile substitution may be also due to regulation. For instance, there are differences across countries with respect to the number of operators, presence of MVNOs, infrastructure sharing policies, regulation of termination rates, etc. ${ }^{22}$ These regulations may influence the level of prices and through this the fixed-to-mobile substitution

\footnotetext{
${ }^{21}$ Dial-up internet (or narrowband) also requires the copper fixed-line network, but it is quickly losing popularity. In our counterfactual we remove both DSL and dial-up.

${ }^{22}$ Mobile Virtual Network Operator (MVNO) is a service provider which does not own the wireless network infrastructure over which it provides services to its customers.
} 
(see Grzybowski (2005) for an analysis of the impact of regulation on prices of mobile services in the EU). In this paper we focus on demand side analysis and therefore cannot make a connection between regulation and fixed-to-mobile substitution. ${ }^{23}$

\section{Conclusion}

In this paper we use a rich survey data of 160,363 households from $27 \mathrm{EU}$ countries in the years 2005-2011 to analyze substitution between access to fixed-line and mobile telecommunications services, and the role of complementarities that may influence this process. We estimate discrete choice models in which households can choose between access to fixed-line and/or mobile voice services, possibly in combination with broadband.

We consider three model specifications. In the first model specification, households only choose between voice services where the choice set consists of 4 alternatives: no telephone, fixed, mobile or both. In the second specification, households choose between voice services from the fixed-line incumbent operator or from competitors, so that the choice set is extended to 9 alternatives. In the third model specification, households simultaneously choose voice and internet technology. There are 19 choice alternatives in this case: the 4 choices of voice from the first specification, which may be combined with at most 6 internet technology choices (including having no internet).

The results from the first and second model specification show that fixed-line connections are in decline because of significant substitution from fixed to mobile telephony: in 2011 mobile telephony reduced fixed-line penetration by $14.1 \%$ points. The degree of substitution is not homogeneous: it varies between households and it is stronger in regions with a high income per capita and in the CEE countries (which may be due to the lower quality of the fixed network than in the WE countries). We also find that the decline has been slowed down because of various complementarities: bundled contracts and incumbency advantages when fixed-line incumbents are also active in mobile telephony. These incumbency advantages increased the incumbent's

\footnotetext{
${ }^{23}$ The variation in prices over time and across countries may be driven by reductions in termination rates. Bourreau et al. (2014) analyze the impact of varying levels of termination rates on consumer subscription decisions to fixed-line and mobile services. Based on numerical simulations they find that each (fixed or mobile) termination rate has a positive effect on the take-up of the corresponding service, via the well-known waterbed effect.
} 
market share by about $2.7 \%$ points in fixed telephony, and by up to $5.4 \%$ points in mobile telephony at the end of 2006. Incumbents could thus not only slow down the fixed-to-mobile substitution process, but also leverage their strong position in fixed telephony into the mobile telephony market. These complementarities did not hurt, but actually benefited total fixed and mobile penetration.

The results from the third model confirm the presence of significant substitution from fixed to mobile telephony. Furthermore, we find that the decline of fixed telephony has been slowed down because of the complementarity of the fixed network with Internet. In particular, without the introduction of DSL, fixed-line voice penetration would have been $8.7 \%$ points lower at the end of 2011. Most of these complementarities arise from the fact that fixed-line and broadband are offered in a bundled contract (enabling price discounts and increased convenience). These findings show that the fixed-line incumbent operator has not only been able to leverage its advantage to mobile voice services, but more importantly also to broadband, since the incumbent typically owns the fixed copper network infrastructure.

Our results suggest that policies towards regulation of broadband market have an impact on the market structure of voice services. We can in general distinguish between two regulatory approaches which result in different market structures of broadband services. One approach is to promote competition on the incumbent's copper network through regulation which provides entrants with access to incumbent's infrastructure via local loop unbundling (service-based competition). ${ }^{24}$ Another approach is to promote deployment and competition between different broadband platforms such as cable modem, fibre, WiFi and more recently mobile broadband (infrastructure-based competition). Some countries opted for service-based competition resulting in high market share of DSL connections, while other pursued infrastructure-based competition with a high market share of other broadband technologies. Due to complementarities with voice services these internet policies led to a different level of penetration of fixed-line and mobile connections.

\footnotetext{
${ }^{24}$ Local loop unbundling is the regulatory process of allowing multiple telecommunications operators to use connections from the telephone exchange to the customer's premises.
} 


\section{References}

Arora, A., 1996. "Testing for complementarities in reduced-form regressions: A note," Economics Letters, 50(1), pp.51-55.

Bourreau, M., Cambini, C. and S. Hoernig 2014. "Fixed-Mobile Substitution and Termination Rates," Mimeo.

Cardona M., Schwarz A., Yurtoglu, B.B. and Ch. Zulehner, 2009. "Demand Estimation and Market Definition for Broadband internet Services," Journal of Regulatory Economics, 35(1), pp.70-95.

Doganoglu, T. and L. Grzybowski, 2007. "Estimating network effects in mobile telephony in Germany," Information Economics and Policy, 19(1), pp.6579.

European Regulators Group (2009), "Report on fixed-mobile convergence: implications on competition and regulatory aspects", ERG (09)06.

Eurobarometer, 2011. "E-Communications Household Survey: Fieldwork February-March 2011," available at http://ec.europa.eu/public_opinion/inde_en.htm.

García-Marinoso, B. and D. Suarez (2013), "Which are the drivers of fixed to mobile telephone access substitution? An empirical study of the Spanish residential market," Telecommunications Policy, 37(4-5), pp.282-291.

Gentzkow, M. 2007 "Valuing New Goods in a Model with Complementarity: Online Newspapers," American Economic Review, 97, pp.713-744.

Gruber, H., 2001. "Competition and Innovation: The Diffusion of Mobile Telecommunications in Central and Eastern Europe," Information Economics and Policy, 13(1), pp.19-34.

Gruber H. and F. Verboven, 2001. "The Diffusion of Mobile Telecommunication Services in the European Union," European Economic Review, 45, pp.577-588.

Grzybowski, L., Nitsche, R., Verboven, F. and L. Wiethaus, 2014. "Market Definition for Broadband internet in Slovakia - Are Fixed and Mobile Technologies in the Same Market?" Information Economics and Policy, 28, pp. 39-56. 
Grzybowski, L., 2014. "Fixed-to-Mobile Substitution in the European Union," Telecommunications Policy, 38(7), pp.601-612.

Hamilton J., 2003. "Are main lines and cell phones substitutes or complements? Evidence. from Africa," Telecommunications Policy, 27, pp.109-133.

Liu, H., Chintagunta, P.K. and T. Zhu, 2010. "Complementarities and the Demand for Home Broadband internet Services," Marketing Science, 29(4), pp.701-720.

Macher, J.T., Mayo, J.W., Ukhaneva, O. and G., Woroch, 2011. "Demand in a Portfolio-Choice Environment: The Evolution of Telecommunications," Georgetown University Working Paper, 1-32.

Miravete, E.J and J.C. Pernas, 2010. "Testing for complementarity when strategies are dichotomous," Economics Letters, 106(1), pp.28-31.

New Zealand Commerce Commission, 2003. "Review of Price Elasticities of Demand for Fixedline and Mobile Telecommunications, " (Wellington: New Zealand Commerce Commission).

Srinuan, P., Srinuan, C. and E., Bohlin, 2012 , Fixed and Mobile Broadband Substitution in Sweden," Telecommunications Policy, 36, pp. 237-251.

Rodini, M., Ward M. and G. Woroch, 2003. "Going Mobile: Substitution Between Fixed and Mobile Access," Telecommunications Policy, 27, pp.457-476.

Samuelson, P., 1974. "Complementarity: An Essay on the 40th Anniversary of the Hicks-Allen Revolution in Demand Theory," Journal of Economic Literature, 12(4), pp. 1255.

Train, K., 2003. "Discrete Choice Methods with Simulation," Cambridge University Press, Cambridge.

Ward, M.R. and G.A. Woroch, 2005. "Fixed-Mobile Telephone Subscription Substitution in the U.S," Working Papers 0501, University of Texas at Arlington, Department of Economics.

Ward, M.R. and G.A. Woroch, 2010. "The effect of prices on fixed and mobile telephone penetration: Using price subsidies as natural experiments," Information Economics and Policy, 22(1), pp.18-32. 
Ward, M.R. and S. Zheng, 2012. "Mobile and fixed substitution for telephone service in China," Telecommunications Policy, 36(4), pp.301-310.

Vogelsang, I., 2010. "The relationship between mobile and fixed-line communications: A survey," Information Economics and Policy, 22(1), pp.4-17. 


\section{Tables and Figures}

Figure 1: Shares of voice technologies across the EU countries

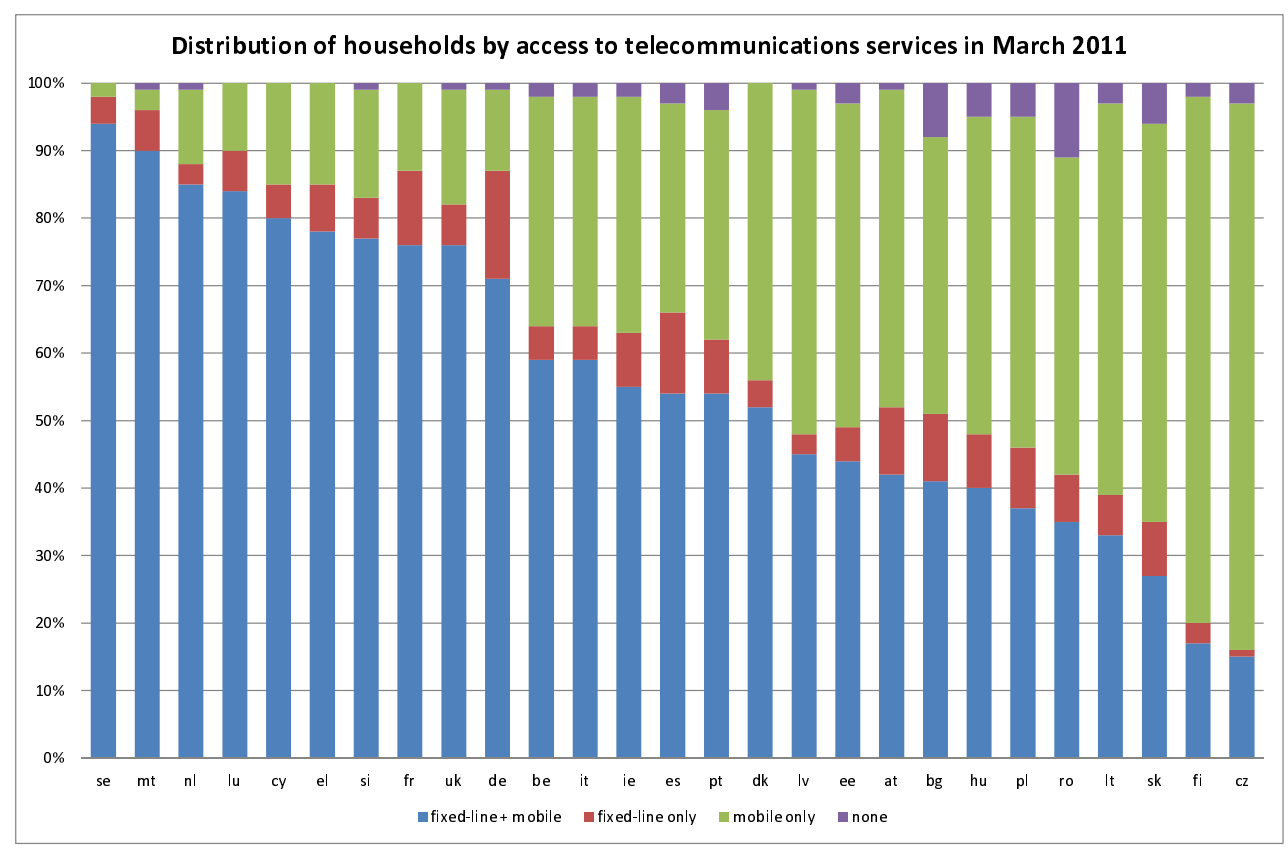

Source: "Eurobarometer: E-Communications Household Surveys", 2011: fieldwork in February-March 2011 


\section{Appendix A}

In this Appendix we describe the model with unobserved heterogeneity for fixed and mobile alternatives. The utilities for the four bundles $r \in\{0, F, M, F+M\}$ are given by:

$$
\begin{aligned}
u_{i 0} & =\epsilon_{i 0} \\
u_{i F} & =\theta_{i F}+x_{i} \beta_{F}+\alpha p_{i F}+\epsilon_{i F} \\
u_{i M} & =\theta_{i M}+x_{i} \beta_{M}+\alpha p_{i M}+\epsilon_{i M} \\
u_{i F+M} & =\left(\theta_{i F}+\theta_{i M}\right)+x_{i}\left(\beta_{F}+\beta_{M}+\gamma\right)+\alpha\left(p_{i F}+p_{i M}\right)+\epsilon_{i F+M}
\end{aligned}
$$

Unobserved preferences for fixed-line and mobile access $j=F, M$ are denoted by the random coefficients vector $\theta_{i}=\left(\theta_{i F}, \theta_{i M}\right)$, which is assumed to follow a bivariate normal distribution with the following mean and covariance matrix:

$$
\left(\begin{array}{c}
\theta_{i F} \\
\theta_{i M}
\end{array}\right) \sim\left(\begin{array}{c}
\theta_{F} \\
\theta_{M}
\end{array}\right),\left(\begin{array}{cc}
\sigma_{F}^{2} & \sigma_{F M} \\
\sigma_{F M} & \sigma_{M}^{2}
\end{array}\right) .
$$

Because the sum of two normal variables is also a normal variable, the vector $\theta_{i}=\left(\theta_{i F}, \theta_{i M}, \theta_{i F}+\right.$ $\left.\theta_{i M}\right)$ has a trivariate normal distribution with mean $\theta$ and covariance matrix $\Sigma$ :

$$
\left(\begin{array}{c}
\theta_{i F} \\
\theta_{i M} \\
\theta_{i F}+\theta_{i M}
\end{array}\right) \sim\left(\begin{array}{c}
\theta_{F} \\
\theta_{M} \\
\theta_{F}+\theta_{M}
\end{array}\right),\left(\begin{array}{ccc}
\sigma_{F}^{2} & \sigma_{F M} & \sigma_{F}^{2}+\sigma_{F M} \\
\sigma_{F M} & \sigma_{M}^{2} & \sigma_{M}^{2}+\sigma_{F M} \\
\sigma_{F}^{2}+\sigma_{F M} & \sigma_{M}^{2}+\sigma_{F M} & \sigma_{F}^{2}+\sigma_{M}^{2}+2 \sigma_{F M}
\end{array}\right) .
$$

Hence, we have a special case of a general mixed logit with trivariate normal distribution, where we impose restrictions on the mean and covariance elements relating to the third option. We can use the Cholesky decomposition $\Sigma=R R^{\prime}$, where $R$ is a lower triangular matrix,

$$
R=\left(\begin{array}{ccc}
r_{1} & 0 & 0 \\
r_{3} & r_{2} & 0 \\
r_{1}+r_{3} & r_{2} & 0
\end{array}\right)
$$

to write the random coefficients vector as $\theta_{i}=\theta+R v_{i}$ where $v_{i}=\left(v_{i F}, v_{i M}, v_{i F}+v_{i M}\right)$ and $v_{i F}$ and $v_{i M}$ are standard normal random variables. After substitution, the above utilities can then 
be written as

$$
\begin{aligned}
u_{i 0} & =\epsilon_{i 0} \\
u_{i F} & =\theta_{F}+r_{1} v_{i F}+x_{i} \beta_{F}+\alpha p_{i F}+\epsilon_{i F} \\
u_{i M} & =\theta_{M}+r_{2} v_{i M}+r_{3} v_{i F}+x_{i} \beta_{M}+\alpha p_{i M}+\epsilon_{i M} \\
u_{i F+M} & =\left(\theta_{F}+\theta_{M}\right)+\left(r_{1}+r_{3}\right) v_{i F}+r_{2} v_{i M}+x_{i}\left(\beta_{F}+\beta_{M}+\gamma\right)+\alpha\left(p_{i F}+p_{i M}\right)+\epsilon_{i F+M} .
\end{aligned}
$$

We estimate the parameters $r_{1}, r_{2}$ and $r_{3}$, from which we can compute the variances $\sigma_{F}^{2}, \sigma_{M}^{2}$ and covariance $\sigma_{F M}$. In practice, we can use a more general Cholesky matrix for three variables

$$
R=\left(\begin{array}{lll}
r_{1} & 0 & 0 \\
r_{3} & r_{2} & 0 \\
r_{6} & r_{5} & r_{4}
\end{array}\right),
$$

and impose restrictions relating to the third option, namely that $r_{4}=0, r_{5}=r_{2}$ and $r_{6}=r_{1}+r_{3}$.

Table 12 shows the parameter estimates for several specifications. We compare a logit and random coefficients in a model without accounting for household characteristics (two left columns) and in a model with accounting for household characteristics (two right columns). To reduce the computational burden, the latter model only includes a selected set of interactions between household characteristics and $\gamma$.

The Table shows that without accounting for the household characteristics, the random coefficients are highly significant, in particular also the standard deviation $\sigma_{F M}$, which is equal to 0.462 with a small standard error of 0.07 ). The price coefficient increases (in absolute value) in the random coefficients model, from -0.042 to -0.058 . In contrast, in the model that accounts for observed household characteristics, the random coefficients become much smaller and are statistically insignificant. In particular, the standard deviation $\sigma_{F M}$ is now 0.106 with a standard error of 0.103 . Furthermore, the price coefficient and other parameters remain very similar when the random coefficients are added. These findings indicate that there is only limited unobserved heterogeneity once the observed household characteristics are added. We therefore focus on the computationally simpler conditional logit model (with also household characteristics interacted with $\gamma$ ) in the main text. 
Table 1: Summary statistics

\begin{tabular}{|c|c|c|c|c|c|}
\hline Variable & Obs. & Mean & Std & Min & Max \\
\hline Cost of mobile (Euros) & 160,363 & 10.6 & 4.9 & 1.18 & 29.7 \\
\hline Cost of fixed-line (Euros) & 160,363 & 36.9 & 7.9 & 16.3 & 57.4 \\
\hline GDP per capita (tsd Euros) & 160,363 & 22.6 & 16 & 2.7 & 250 \\
\hline Male & 160,363 & 0.45 & 0.5 & 0 & 1 \\
\hline Married & 160,363 & 0.52 & 0.5 & 0 & 1 \\
\hline Age $\leq 24$ & 160,363 & 0.12 & 0.3 & 0 & 1 \\
\hline Age $>24$ and $\leq 34$ & 160,363 & 0.15 & 0.4 & 0 & 1 \\
\hline Age $>34$ and $\leq 44$ & 160,363 & 0.17 & 0.4 & 0 & 1 \\
\hline Age $>44$ and $\leq 54$ & 160,363 & 0.17 & 0.4 & 0 & 1 \\
\hline Age $>54$ and $\leq 64$ & 160,363 & 0.17 & 0.4 & 0 & 1 \\
\hline Age $>64$ (base) & 160,363 & 0.22 & 0.4 & 0 & 1 \\
\hline Household size & 160,363 & 2.51 & 1.1 & 1 & 4 \\
\hline Number of kids & 160,237 & 0.16 & 0.4 & 0 & 4 \\
\hline Education years $\leq 15$ & 160,363 & 0.2 & 0.4 & 0 & 1 \\
\hline Education years $>15$ and $<20$ & 160,363 & 0.43 & 0.5 & 0 & 1 \\
\hline Education years $20+$ & 160,363 & 0.27 & 0.4 & 0 & 1 \\
\hline Living in rural area (base) & 160,363 & 0.36 & 0.5 & 0 & 1 \\
\hline Living in town & 160,363 & 0.28 & 0.4 & 0 & 1 \\
\hline Living in city & 160,363 & 0.37 & 0.5 & 0 & 1 \\
\hline Profession: unemployed (base) & 160,363 & 0.08 & 0.3 & 0 & 1 \\
\hline Profession: housekeeping & 160,363 & 0.07 & 0.3 & 0 & 1 \\
\hline Profession: student & 160,363 & 0.08 & 0.3 & 0 & 1 \\
\hline Profession: retired & 160,363 & 0.29 & 0.5 & 0 & 1 \\
\hline Profession: office employee & 160,363 & 0.08 & 0.3 & 0 & 1 \\
\hline Profession: professional & 160,363 & 0.04 & 0.2 & 0 & 1 \\
\hline Profession: manual worker & 160,363 & 0.14 & 0.3 & 0 & 1 \\
\hline Profession: proprietor & 160,363 & 0.04 & 0.2 & 0 & 1 \\
\hline Profession: manager & 160,363 & 0.07 & 0.3 & 0 & 1 \\
\hline Profession: farmer & 160,363 & 0.01 & 0.1 & 0 & 1 \\
\hline Profession: travelling & 160,363 & 0.1 & 0.3 & 0 & 1 \\
\hline Internet access: DSL & 160,363 & 0.26 & 0.4 & 0 & 1 \\
\hline Internet access: cable & 160,363 & 0.12 & 0.3 & 0 & 1 \\
\hline Internet access: dial-up & 160,363 & 0.09 & 0.3 & 0 & 1 \\
\hline Internet access: mobile & 160,363 & 0.03 & 0.2 & 0 & 1 \\
\hline Internet access: other & 160,363 & 0.03 & 0.2 & 0 & 1 \\
\hline
\end{tabular}

Base variable is indicated for dummy variables. In the case of Education years dummies, the reference are households without education or with missing information. 
Table 2: Choice of voice technologies

\begin{tabular}{|l|l||c|c||c|}
\hline \hline & & Fixed-line & & \\
\hline & & No & Yes & Total \\
\hline \hline Mobile & No & 5,775 & 19,567 & 25,342 \\
\hline & Yes & 46,471 & 88,550 & 135,021 \\
\hline \hline & Total & 52,246 & 108,117 & 160,363 \\
\hline \hline
\end{tabular}

Table 3: Choice of voice technologies offered by incumbent and competitor

\begin{tabular}{|l|l||c|c|c||c|}
\hline \hline & & Fixed-line & & & \\
\hline & & None & Incumbent & Competitor & Total \\
\hline \hline Mobile & None & 3,297 & 8,459 & 835 & 12,591 \\
\hline & Incumbent & 4,091 & 10,227 & 1,423 & 15,741 \\
\hline & Competitor & 8,993 & 12,995 & 3,086 & 25,074 \\
\hline \hline & Total & 16,381 & 31,681 & 5,344 & 53,406 \\
\hline \hline
\end{tabular}

Table 4: Choice of voice and broadband technologies

\begin{tabular}{|l||c|c|c|c|c|c||c|}
\hline \hline & DSL & Dial-up & Cable modem & Mobile & Other & None & Total \\
\hline \hline Mobile only & 6,210 & 1,155 & 7,183 & 3,019 & 3,008 & 26,710 & 47,285 \\
\hline Fixed-line only & 1,325 & 774 & 497 & 50 & 129 & 16,861 & 19,636 \\
\hline Mobile+ Fixed-line & 33,470 & 12,253 & 11,447 & 2,259 & 2,656 & 29,133 & 91,218 \\
\hline None & 79 & 26 & 88 & 15 & 29 & 5,544 & 5,781 \\
\hline \hline Total & 41,084 & 14,208 & 19,215 & 5,343 & 5,822 & 78,248 & 163,920 \\
\hline \hline
\end{tabular}

The total number 163,920 is greater than the number of observations 160,363 because of some households having more than one internet technology.

Table 5: Households with connections to different internet technologies

\begin{tabular}{|l||c|c|c|c|c|c||c|}
\hline \hline & DSL & Dial-up & Cable modem & Mobile & Other & None & Total \\
\hline \hline DSL & 0 & 740 & 307 & 1,091 & 134 & 38,812 & 41,084 \\
\hline Dial-up & & 98 & 141 & 179 & 59 & 12,893 & 13,370 \\
\hline Cable modem & & & 0 & 447 & 80 & 18,240 & 18,767 \\
\hline Mobile & & & & 0 & 95 & 3,531 & 3,626 \\
\hline Other & & & & & 186 & 5,082 & 5,268 \\
\hline None & & & & & & 78,248 & 78,248 \\
\hline & & & & & & & 160,363 \\
\hline \hline
\end{tabular}


Table 6: Choice model for voice services

\begin{tabular}{|c|c|c|c|c|c|c|}
\hline & \multicolumn{3}{|c|}{ Base model } & \multicolumn{3}{|c|}{ Base model + Incumbent } \\
\hline & Mobile & Fixed-line & Mobile+Fixed $(\gamma)$ & Mobile & Fixed-line & Mobile+Fixed $(\gamma)$ \\
\hline Price & $\begin{array}{c}-0.056^{* * *} \\
(0.002)\end{array}$ & $\begin{array}{c}-0.056^{* * *} \\
(0.002)\end{array}$ & & $\begin{array}{c}-0.041^{* * *} \\
(0.003)\end{array}$ & $\begin{array}{c}-0.041^{* * *} \\
(0.003)\end{array}$ & \\
\hline Price residual & $\begin{array}{c}0.022^{* * *} \\
(0.002)\end{array}$ & $\begin{array}{c}0.022^{* * *} \\
(0.002)\end{array}$ & & $\begin{array}{l}-0.001 \\
(0.004)\end{array}$ & $\begin{array}{l}-0.001 \\
(0.004)\end{array}$ & \\
\hline Intercept & $\begin{array}{c}-0.423^{* * *} \\
(0.105)\end{array}$ & $\begin{array}{c}3.642^{* * *} \\
(0.123)\end{array}$ & $\begin{array}{c}-0.733^{* * *} \\
(0.114)\end{array}$ & $\begin{array}{c}-1.425^{* * *} \\
(0.153)\end{array}$ & $\begin{array}{c}0.716^{* * *} \\
(0.182)\end{array}$ & $\begin{array}{l}-0.238 \\
(0.166)\end{array}$ \\
\hline CEE dummy & $\begin{array}{c}0.132^{* * *} \\
(0.027)\end{array}$ & $\begin{array}{c}-0.621^{* * *} \\
(0.033)\end{array}$ & $\begin{array}{c}-0.409^{* * *} \\
(0.038)\end{array}$ & $\begin{array}{c}-0.158^{* *} \\
(0.080)\end{array}$ & $\begin{array}{c}-1.073^{* * *} \\
(0.079)\end{array}$ & $\begin{array}{c}0.225^{* *} \\
(0.089)\end{array}$ \\
\hline GDP per capita & $\begin{array}{c}1.412^{* * *} \\
(0.029)\end{array}$ & $\begin{array}{c}1.234^{* * *} \\
(0.032)\end{array}$ & $\begin{array}{c}-0.835^{* * *} \\
(0.034)\end{array}$ & $\begin{array}{c}0.956^{* * *} \\
(0.051)\end{array}$ & $\begin{array}{c}0.410^{* * *} \\
(0.050)\end{array}$ & $\begin{array}{c}-0.138^{* *} \\
(0.057)\end{array}$ \\
\hline Bundle & & & $\begin{array}{c}2.153^{* * *} \\
(0.048)\end{array}$ & & & $\begin{array}{c}1.442^{* * *} \\
(0.072)\end{array}$ \\
\hline Incumbent & & & & $\begin{array}{c}-0.517^{* * *} \\
(0.017)\end{array}$ & $\begin{array}{c}1.334^{* * *} \\
(0.016)\end{array}$ & $\begin{array}{c}0.398^{* * *} \\
(0.021)\end{array}$ \\
\hline Year dummy: 2006 & $\begin{array}{c}0.055 \\
(0.046)\end{array}$ & $\begin{array}{c}-0.431^{* * *} \\
(0.047)\end{array}$ & $\begin{array}{l}0.090^{*} \\
(0.051)\end{array}$ & $\begin{array}{c}0.102^{* *} \\
(0.043)\end{array}$ & $\begin{array}{c}-0.282^{* * *} \\
(0.043)\end{array}$ & $\begin{array}{l}-0.002 \\
(0.048)\end{array}$ \\
\hline Year dummy: 2007 & $\begin{array}{c}0.219^{* * *} \\
(0.048)\end{array}$ & $\begin{array}{c}-0.630^{* * *} \\
(0.049)\end{array}$ & $\begin{array}{c}0.194^{* * *} \\
(0.053)\end{array}$ & & & \\
\hline Year dummy: 2009 & $\begin{array}{c}1.068^{* * *} \\
(0.054)\end{array}$ & $\begin{array}{c}-0.200^{* * *} \\
(0.055)\end{array}$ & $\begin{array}{c}-0.353^{* * *} \\
(0.058)\end{array}$ & & & \\
\hline Year dummy: 2010 & $\begin{array}{c}1.289^{* * *} \\
(0.056)\end{array}$ & $\begin{array}{c}-0.378^{* * *} \\
(0.059)\end{array}$ & $\begin{array}{c}-0.212^{* * *} \\
(0.062)\end{array}$ & & & \\
\hline Year dummy: 2011 & $\begin{array}{c}1.309^{* * *} \\
(0.055)\end{array}$ & $\begin{array}{c}-0.409^{* * *} \\
(0.058)\end{array}$ & $\begin{array}{c}-0.260^{* * *} \\
(0.061)\end{array}$ & & & \\
\hline Observations & 641,452 & & & 405,902 & & \\
\hline Number of households & 130,363 & & & 53,199 & & \\
\hline
\end{tabular}

Base model: choices of voice connections with substitution parameters for two groups of CEE and WE countries. The regressions include household characteristics which are reported in Table 7. Base model + incumbent: choices of voice connections from incumbent vs. competitor. The regression includes household characteristics which are reported in Table B.5.

Standard errors in parentheses, ${ }^{* * *} p<0.01,{ }^{* *} p<0.05,{ }^{*} p<0.1$ 
Table 7: Choice model for voice services: household characteristics effects

\begin{tabular}{|c|c|c|c|}
\hline & \multicolumn{3}{|c|}{ Base model } \\
\hline & Mobile & Fixed-line & Mobile+Fixed $(\gamma)$ \\
\hline Living in city & $\begin{array}{c}0.742^{* * *} \\
(0.043)\end{array}$ & $\begin{array}{c}0.627^{* * *} \\
(0.045)\end{array}$ & $\begin{array}{c}-0.469^{* * *} \\
(0.047)\end{array}$ \\
\hline Living in town & $\begin{array}{c}0.516^{* * *} \\
(0.035)\end{array}$ & $\begin{array}{c}0.247^{* * *} \\
(0.036)\end{array}$ & $\begin{array}{c}-0.276^{* * *} \\
(0.039)\end{array}$ \\
\hline Male & $\begin{array}{c}-0.372^{* * *} \\
(0.032)\end{array}$ & $\begin{array}{c}-0.557^{* * *} \\
(0.034)\end{array}$ & $\begin{array}{c}0.501^{* * *} \\
(0.036)\end{array}$ \\
\hline Married & $\begin{array}{c}0.387^{* * *} \\
(0.037)\end{array}$ & $\begin{array}{c}0.343^{* * *} \\
(0.039)\end{array}$ & $\begin{array}{l}-0.078^{*} \\
(0.041)\end{array}$ \\
\hline Household size & $\begin{array}{c}0.129^{* * *} \\
(0.021)\end{array}$ & $\begin{array}{c}0.304^{* * *} \\
(0.023)\end{array}$ & $\begin{array}{c}0.078^{* * *} \\
(0.024)\end{array}$ \\
\hline Number of kids & $\begin{array}{c}-0.133^{* * *} \\
(0.044)\end{array}$ & $\begin{array}{c}-0.288^{* * *} \\
(0.051)\end{array}$ & $\begin{array}{c}0.176^{* * *} \\
(0.053)\end{array}$ \\
\hline Age $>24$ and $\leq 34$ & $\begin{array}{c}1.980^{* * *} \\
(0.093)\end{array}$ & $\begin{array}{c}-2.266^{* * *} \\
(0.120)\end{array}$ & $\begin{array}{c}0.539^{* * *} \\
(0.125)\end{array}$ \\
\hline Age $>34$ and $\leq 44$ & $\begin{array}{c}2.032^{* * *} \\
(0.078)\end{array}$ & $\begin{array}{c}-2.076^{* * *} \\
(0.091)\end{array}$ & $\begin{array}{l}0.222^{* *} \\
(0.096)\end{array}$ \\
\hline Age $>44$ and $\leq 54$ & $\begin{array}{c}1.568^{* * *} \\
(0.073)\end{array}$ & $\begin{array}{c}-1.543^{* * *} \\
(0.080)\end{array}$ & $\begin{array}{c}0.116 \\
(0.085)\end{array}$ \\
\hline Age $>54$ and $\leq 64$ & $\begin{array}{c}1.091^{* * *} \\
(0.062)\end{array}$ & $\begin{array}{c}-1.056^{* * *} \\
(0.064)\end{array}$ & $\begin{array}{l}0.095 \\
(0.070)\end{array}$ \\
\hline Age $>64$ & $\begin{array}{c}0.906^{* * *} \\
(0.047)\end{array}$ & $\begin{array}{c}-0.485^{* * *} \\
(0.046)\end{array}$ & $\begin{array}{c}0.006 \\
(0.052)\end{array}$ \\
\hline Education years 15- & $\begin{array}{c}0.341 * * * \\
(0.071)\end{array}$ & $\begin{array}{c}0.332 * * * \\
(0.069)\end{array}$ & $\begin{array}{c}-0.285^{* * *} \\
(0.083)\end{array}$ \\
\hline Education years $>15$ and $\leq 20$ & $\begin{array}{c}1.107^{* * *} \\
(0.072)\end{array}$ & $\begin{array}{c}0.778^{* * *} \\
(0.071)\end{array}$ & $\begin{array}{c}-0.337^{* * *} \\
(0.083)\end{array}$ \\
\hline Education years $20+$ & $\begin{array}{c}1.699^{* * *} \\
(0.086)\end{array}$ & $\begin{array}{c}1.280^{* * *} \\
(0.086)\end{array}$ & $\begin{array}{c}-0.493^{* * *} \\
(0.097)\end{array}$ \\
\hline Profession: housekeeping & $\begin{array}{l}-0.058 \\
(0.071)\end{array}$ & $\begin{array}{c}-0.593^{* * *} \\
(0.081)\end{array}$ & $\begin{array}{c}0.355^{* * *} \\
(0.086)\end{array}$ \\
\hline Prefession: student & $\begin{array}{c}2.081^{* * *} \\
(0.136)\end{array}$ & $\begin{array}{c}1.256^{* * *} \\
(0.167)\end{array}$ & $\begin{array}{l}-0.161 \\
(0.175)\end{array}$ \\
\hline Profession: retired & $\begin{array}{c}0.184^{* * *} \\
(0.066)\end{array}$ & $\begin{array}{c}0.004 \\
(0.066)\end{array}$ & $\begin{array}{l}0.140^{*} \\
(0.072)\end{array}$ \\
\hline Profession: office employee & $\begin{array}{c}1.413^{* * *} \\
(0.124)\end{array}$ & $\begin{array}{c}0.603^{* * *} \\
(0.134)\end{array}$ & $\begin{array}{l}-0.228^{*} \\
(0.137)\end{array}$ \\
\hline Profession: professional & $\begin{array}{c}1.170^{* * *} \\
(0.161)\end{array}$ & $\begin{array}{c}0.185 \\
(0.179)\end{array}$ & $\begin{array}{l}0.378^{* *} \\
(0.182)\end{array}$ \\
\hline Profession: manual worker & $\begin{array}{c}0.779 * * * \\
(0.071)\end{array}$ & $\begin{array}{c}0.067 \\
(0.077)\end{array}$ & $\begin{array}{l}-0.097 \\
(0.081)\end{array}$ \\
\hline Profession: proprietor & $\begin{array}{c}1.828^{* * *} \\
(0.175)\end{array}$ & $\begin{array}{c}1.058^{* * *} \\
(0.185)\end{array}$ & $\begin{array}{c}-0.515^{* * *} \\
(0.188)\end{array}$ \\
\hline Profession: manager & $\begin{array}{c}1.263^{* * *} \\
(0.143)\end{array}$ & $\begin{array}{c}0.674^{* * *} \\
(0.151)\end{array}$ & $\begin{array}{c}-0.260^{*} \\
(0.154)\end{array}$ \\
\hline Profession: farmer & $\begin{array}{l}-0.066 \\
(0.114)\end{array}$ & $\begin{array}{c}0.289^{* *} \\
(0.118)\end{array}$ & $\begin{array}{c}0.135 \\
(0.132)\end{array}$ \\
\hline Profession: travelling & $\begin{array}{c}1.387^{* * *} \\
(0.105)\end{array}$ & $\begin{array}{c}0.590^{* * *} \\
(0.113)\end{array}$ & $\begin{array}{c}-0.415^{* * *} \\
(0.116)\end{array}$ \\
\hline $\begin{array}{l}\text { Observations } \\
\text { Households }\end{array}$ & $\begin{array}{l}640,948 \\
160,363\end{array}$ & & \\
\hline
\end{tabular}

Base model: choices of voice connections with substitution parameters for two groups of CEE and WE countries.

Standard errors in parentheses, ${ }^{* * *} p<0.01,{ }^{* *} p<0.05,{ }^{*} p<0.1$ 
Table 8: Own and cross price elasticities

\begin{tabular}{|l||c|c|}
\hline \hline & Fixed-line & Mobile \\
\hline \hline Fixed-line & -0.43 & 0.021 \\
\hline Mobile & 0.021 & -0.21 \\
\hline \hline
\end{tabular}

Table 9: Choice model for voice services and broadband internet

\begin{tabular}{|c|c|c|c|c|c|c|}
\hline & \multicolumn{6}{|c|}{ Base model + Broadband } \\
\hline & Mobile & Fixed-line & $\begin{array}{c}\text { Mobile } \\
+ \text { Fixed }(\gamma) \\
\end{array}$ & Broadband & $\begin{array}{c}\text { Broadband } \\
+ \text { Mobile }\left(\delta_{M}\right)\end{array}$ & $\begin{array}{l}\text { Broadband } \\
+ \text { Fixed }\left(\delta_{F}\right) \\
\end{array}$ \\
\hline Price & $\begin{array}{c}-0.053^{* * *} \\
(0.002)\end{array}$ & $\begin{array}{c}-0.053^{* * *} \\
(0.002)\end{array}$ & & & & \\
\hline Price residual & $\begin{array}{c}0.017^{* * *} \\
(0.002)\end{array}$ & $\begin{array}{c}0.017^{* * *} \\
(0.002)\end{array}$ & & & & \\
\hline Intercept & $\begin{array}{c}-0.714^{* * *} \\
(0.108)\end{array}$ & $\begin{array}{c}3.583^{* * *} \\
(0.127)\end{array}$ & $\begin{array}{c}-0.278^{* *} \\
(0.116)\end{array}$ & & & \\
\hline CEE dummy & $\begin{array}{c}0.123^{* * *} \\
(0.029)\end{array}$ & $\begin{array}{c}-0.621^{* * *} \\
(0.034)\end{array}$ & $\begin{array}{c}-0.394^{* * *} \\
(0.039)\end{array}$ & & & \\
\hline GDP per capita & $\begin{array}{c}1.371^{* * *} \\
(0.030)\end{array}$ & $\begin{array}{c}1.120^{* * *} \\
(0.033)\end{array}$ & $\begin{array}{c}-0.976^{* * *} \\
(0.035)\end{array}$ & $\begin{array}{c}0.814^{* * *} \\
(0.010)\end{array}$ & & \\
\hline Dial-up connection & & & & $\begin{array}{c}-8.016^{* * *} \\
(0.078)\end{array}$ & $\begin{array}{c}1.032^{* * *} \\
(0.041)\end{array}$ & $\begin{array}{c}2.465^{* * *} \\
(0.035)\end{array}$ \\
\hline DSL connection & & & & $\begin{array}{c}-6.782^{* * *} \\
(0.068)\end{array}$ & $\begin{array}{c}1.519^{* * *} \\
(0.032)\end{array}$ & $\begin{array}{c}1.782^{* * *} \\
(0.019)\end{array}$ \\
\hline Cable connection & & & & $\begin{array}{c}-6.522^{* * *} \\
(0.078)\end{array}$ & $\begin{array}{c}1.421^{* * * *} \\
(0.049)\end{array}$ & $\begin{array}{c}0.545^{* * *} \\
(0.020)\end{array}$ \\
\hline Mobile broadband & & & & $\begin{array}{c}-7.907^{* * *} \\
(0.196)\end{array}$ & $\begin{array}{c}1.795^{* * *} \\
(0.186)\end{array}$ & $\begin{array}{c}-0.840^{* * *} \\
(0.040)\end{array}$ \\
\hline Other broadband & & & & $\begin{array}{c}-7.279^{* * *} \\
(0.113)\end{array}$ & $\begin{array}{c}1.266^{* * *} \\
(0.094)\end{array}$ & $\begin{array}{c}-0.066^{* *} \\
(0.031)\end{array}$ \\
\hline Bundle & & & $\begin{array}{c}1.564^{* * *} \\
(0.054)\end{array}$ & & $\begin{array}{c}0.648^{* * *} \\
(0.096)\end{array}$ & $\begin{array}{c}3.497^{* * *} \\
(0.041)\end{array}$ \\
\hline Year dummy: 2006 & & & $\begin{array}{c}0.024 \\
(0.052)\end{array}$ & $\begin{array}{c}0.158^{* * *} \\
(0.022)\end{array}$ & $\begin{array}{c}0.085^{*} \\
(0.047)\end{array}$ & $\begin{array}{c}-0.439 * * * \\
(0.047)\end{array}$ \\
\hline Year dummy: 2007 & & & $\begin{array}{c}0.003 \\
(0.054)\end{array}$ & $\begin{array}{c}0.514^{* * *} \\
(0.022)\end{array}$ & $\begin{array}{c}0.278^{* * *} \\
(0.049)\end{array}$ & $\begin{array}{c}-0.682^{* * *} \\
(0.050)\end{array}$ \\
\hline Year dummy: 2009 & & & $\begin{array}{c}-0.726^{* * *} \\
(0.060)\end{array}$ & $\begin{array}{c}1.143^{* * *} \\
(0.023)\end{array}$ & $\begin{array}{c}1.134^{* * *} \\
(0.055)\end{array}$ & $\begin{array}{c}-0.392^{* * *} \\
(0.056)\end{array}$ \\
\hline Year dummy: 2010 & & & $\begin{array}{c}-0.693^{* * *} \\
(0.064)\end{array}$ & $\begin{array}{c}1.540^{* * *} \\
(0.023)\end{array}$ & $\begin{array}{c}1.354^{* * *} \\
(0.059)\end{array}$ & $\begin{array}{c}-0.641^{* * *} \\
(0.061)\end{array}$ \\
\hline Year dummy: 2011 & & & $\begin{array}{c}-0.741^{* * *} \\
(0.063)\end{array}$ & $\begin{array}{c}1.549^{* * *} \\
(0.023)\end{array}$ & $\begin{array}{c}1.373^{* * *} \\
(0.058)\end{array}$ & $\begin{array}{c}-0.670^{* * *} \\
(0.060)\end{array}$ \\
\hline $\begin{array}{l}\text { Observations } \\
\text { Households }\end{array}$ & $\begin{array}{c}2,980,416 \\
130,363\end{array}$ & & & & & \\
\hline
\end{tabular}

Base model + Broadband: choices of voice and broadband connections. The regression include household characteristics which are reported in Table B.5.

Standard errors in parentheses, ${ }^{* * *} p<0.01,{ }^{* *} p<0.05,{ }^{*} p<0.1$ 
Table 10: The impact of mobile on fixed-line and mobile: predicted penetration in 2006 and 2011

\begin{tabular}{|c|c|c|c|c|}
\hline & \multicolumn{4}{|c|}{2006} \\
\hline & mobile (std) & fixed-line (std) & mobile+fixed (std) & none (std) \\
\hline current & $77.9 \%(0.8 \%)$ & $66.9 \%(0.7 \%)$ & $51.0 \%(0.5 \%)$ & $6.2 \%(0.1 \%)$ \\
\hline of which incumbent & $38.1 \%(0.4 \%)$ & $57.5 \%(0.5 \%)$ & & \\
\hline no mobile & $0.0 \%(0.0 \%)$ & $72.8 \%(0.8 \%)$ & $0.0 \%(0.0 \%)$ & $27.2 \%(0.7 \%)$ \\
\hline of which incumbent & $0.0 \%(0.0 \%)$ & $61.5 \%(0.6 \%)$ & & \\
\hline mobile price as in 2006 & $77.8 \%(0.8 \%)$ & $66.9 \%(0.7 \%)$ & $50.9 \%(0.5 \%)$ & $6.2 \%(0.1 \%)$ \\
\hline of which incumbent & $37.4 \%(0.4 \%)$ & $57.4 \%(0.5 \%)$ & & \\
\hline no fixed-mobile bundle & $77.7 \%(0.8 \%)$ & $66.4 \%(0.7 \%)$ & $50.3 \%(0.5 \%)$ & $6.2 \%(0.1 \%)$ \\
\hline of which incumbent & $38.1 \%(0.4 \%)$ & $57.0 \%(0.5 \%)$ & & \\
\hline no incumbent's fixed-mobile advantage & $76.9 \%(0.8 \%)$ & $65.0 \%(0.7 \%)$ & $48.3 \%(0.5 \%)$ & $6.4 \%(0.1 \%)$ \\
\hline of which incumbent & $32.7 \%(0.4 \%)$ & $54.8 \%(0.6 \%)$ & & \\
\hline \multirow{4}{*}{$\begin{array}{l}\text { no incumbent's mobile } \\
\text { of which incumbent }\end{array}$} & $71.1 \%(0.6 \%)$ & $65.7 \%(0.6 \%)$ & $44.5 \%(0.4 \%)$ & $7.7 \%(0.2 \%)$ \\
\hline & $0.0 \%(0.0 \%)$ & $55.5 \%(0.5 \%)$ & & \\
\hline & \multicolumn{4}{|c|}{2011} \\
\hline & mobile (std) & fixed-line (std) & mobile+fixed (std) & none (std) \\
\hline $\begin{array}{l}\text { current } \\
\text { of which incumbent }\end{array}$ & $89.9 \%(0.5 \%)$ & $63.1 \%(0.4 \%)$ & $53.4 \%(0.3 \%)$ & $2.4 \%(0.1 \%)$ \\
\hline $\begin{array}{l}\text { no mobile } \\
\text { of which incumbent }\end{array}$ & $0.0 \%(0.0 \%)$ & $77.3 \%(0.7 \%)$ & $0.0 \%(0.0 \%)$ & $22.7 \%(0.7 \%)$ \\
\hline $\begin{array}{l}\text { mobile price as in } 2006 \\
\text { of which incumbent }\end{array}$ & $88.5 \%(0.5 \%)$ & $63.3 \%(0.4 \%)$ & $52.9 \%(0.3 \%)$ & $2.6 \%(0.1 \%)$ \\
\hline $\begin{array}{l}\text { no fixed-mobile bundle } \\
\text { of which incumbent }\end{array}$ & $89.7 \%(0.6 \%)$ & $61.9 \%(0.4 \%)$ & $52.5 \%(0.0 \%)$ & $2.4 \%(0.1 \%)$ \\
\hline $\begin{array}{l}\text { no incumbent's fixed-mobile advantage } \\
\text { of which incumbent }\end{array}$ & n.a. & n.a. & n.a. & n.a. \\
\hline $\begin{array}{l}\text { no incumbent's mobile } \\
\text { of which incumbent }\end{array}$ & n.a. & n.a. & n.a. & n.a. \\
\hline
\end{tabular}

Predicted mobile and fixed-line penetration for: (i) Current: current situation; (ii) No mobiles: no mobile telephones available; (iii) Mobile prices as in 2005; (iv) No mobile+fixed bundle: zero value of mobile+fixed bundle; (v) No incumbent's fixed-mobile advantage: no additional utility from using mobile and fixed-line from incumbent. The standard deviations are calculated for 100 random draws from the distribution of parameters. 
Table 11: The impact of broadband on fixed-line: predicted mobile and fixed-line penetration in 2006 and 2011

\begin{tabular}{|l||c|c|c|c||}
\hline \hline \multicolumn{1}{|c||}{} & \multicolumn{5}{c||}{2006} \\
\hline & mobile (std) & fixed-line (std) & mobile+fixed (std) & none (std) \\
\hline \hline Current & $79.0 \%(0.9 \%)$ & $69.1 \%(0.8 \%)$ & $53.1 \%(0.5 \%)$ & $5.0 \%(0.1 \%)$ \\
No Internet & $75.8 \%(0.6 \%)$ & $61.9 \%(0.5 \%)$ & $43.6 \%(0.3 \%)$ & $5.9 \%(0.1 \%)$ \\
No DSL & $77.5 \%(0.8 \%)$ & $62.7 \%(0.7 \%)$ & $45.7 \%(0.5 \%)$ & $5.5 \%(0.1 \%)$ \\
No bundle fixed+Internet & $79.1 \%(0.9 \%)$ & $66.5 \%(0.8 \%)$ & $50.8 \%(0.5 \%)$ & $5.1 \%(0.1 \%)$ \\
No bundle mobile+Internet & $79.0 \%(0.9 \%)$ & $69.1 \%(0.8 \%)$ & $53.1 \%(0.5 \%)$ & $5.0 \%(0.1 \%)$ \\
\hline \hline \multicolumn{5}{|c|}{2011} \\
\hline Current & mobile (std) & fixed-line (std) & mobile+fixed (std) & none (std) \\
No Internet & $89.9 \%(1.1 \%)$ & $63.0 \%(0.8 \%)$ & $55.1 \%(0.6 \%)$ & $2.3 \%(0.1 \%)$ \\
No DSL & $86.4 \%(0.6 \%)$ & $53.2 \%(0.5 \%)$ & $42.7 \%(0.3 \%)$ & $3.1 \%(0.1 \%)$ \\
No bundle fixed+Internet & $88.6 \%(1.1 \%)$ & $54.3 \%(0.8 \%)$ & $45.5 \%(0.6 \%)$ & $2.6 \%(0.1 \%)$ \\
No bundle mobile+Internet & $90.3 \%(1.2 \%)$ & $53.2 \%(0.7 \%)$ & $45.9 \%(0.5 \%)$ & $2.4 \%(0.1 \%)$ \\
\hline \hline
\end{tabular}

Predicted mobile and fixed-line penetration for: (i) Current: current situation; (ii) No broadband: no broadband available (iii) No DSL: no DSL broadband available; (iv) No bundle fixed+internet: zero value of fixed+internet bundle. The standard deviations are calculated for 100 random draws from the distribution of parameters.

Table 12: Choice model for voice services: comparison logit and random coefficients logit

\begin{tabular}{|l||c|c||c|c|}
\hline \hline \multicolumn{1}{|c||}{} & \multicolumn{1}{l|}{ no household characteristics } & household characteristics \\
\hline \hline \multicolumn{1}{|l||}{$\sigma_{M}^{2}$} & logit & rc logit & logit & rc logit \\
\hline \multicolumn{1}{|l|}{$\sigma_{M F}$} & & $0.849^{* * *}$ & & $0.293^{* *}$ \\
& & $(0.111)$ & & $(0.145)$ \\
\hline$\sigma_{F}^{2}$ & & $0.626^{* * *}$ & & 0,053 \\
& & $(0.040)$ & & $(0.089)$ \\
\hline Price & & $0.462^{* * *}$ & & 0,106 \\
& & $(0.072)$ & & $(0.103)$ \\
\hline$\theta_{M}$ & $-0.042^{* * *}$ & $-0.058^{* * *}$ & $-0.040^{* * *}$ & $-0.046^{* * *}$ \\
& $(0.001)$ & $(0.001)$ & $(0.002)$ & $(0.003)$ \\
\hline$\theta_{F}$ & $2.831^{* * *}$ & $4.133^{* * *}$ & $-0.811^{* * *}$ & $-0.883^{* * *}$ \\
& $(0.018)$ & $(0.069)$ & $(0.133)$ & $(0.175)$ \\
\hline$\gamma$ & $3.344^{* * *}$ & $4.910^{* * *}$ & $2.770^{* * *}$ & $2.973^{* * *}$ \\
& $(0.033)$ & $(0.089)$ & $(0.134)$ & $(0.179)$ \\
\hline CEE (M, F and F+M) & $-0.782^{* * *}$ & $-1.488^{* * *}$ & $-0.506^{* * *}$ & $-0.694^{* * *}$ \\
& $(0.017)$ & $(0.037)$ & $(0.043)$ & $(0.112)$ \\
\hline GDP (M, F and F+M) & included & included & included & included \\
& & & & \\
\hline Household characteristics & included & included & included & included \\
& & & & \\
\hline \hline Observations & 641,452 & 641,452 & 128,188 & 128,188 \\
\hline
\end{tabular}

Standard errors in parentheses, ${ }^{* * *} p<0.01,{ }^{* *} p<0.05,{ }^{*} p<0.1$. For computational reasons we use only $20 \%$ of the total sample in the estimation of random coefficients mode. 


\section{Appendix B}

Table B.1: Sample size by country

\begin{tabular}{|l||c|c|c|c|c|c||c|}
\hline \hline & 2005 & 2006 & 2007 & 2009 & 2010 & 2011 & Sum \\
\hline \hline Austria & 1,019 & 1,029 & 1,012 & 1,001 & 1,030 & 1,047 & 6,138 \\
Belgium & 1,011 & 1,009 & 1,004 & 1,003 & 1,025 & 1,033 & 6,085 \\
Bulgaria & 1,002 & 1,023 & 1,000 & 1,007 & 1,001 & 1,001 & 6,034 \\
Cyprus & 507 & 504 & 505 & 502 & 500 & 503 & 3,021 \\
Czech Republic & 1,012 & 1150 & 1169 & 1,096 & 1,014 & 995 & 6,436 \\
Germany & 1,515 & 1,504 & 1,519 & 1,522 & 1,622 & 1,562 & 9,244 \\
Denmark & 1,039 & 1,037 & 1,000 & 1,008 & 1,013 & 1,011 & 6,108 \\
Estonia & 1,000 & 1,000 & 1,002 & 1,000 & 1,003 & 1,000 & 6,005 \\
Greece & 999 & 1,000 & 1,000 & 1,000 & 1,000 & 999 & 5,998 \\
Spain & 1,000 & 1,000 & 1,000 & 1,023 & 1,004 & 1,010 & 6,037 \\
Finland & 1,023 & 1,028 & 1,038 & 1,041 & 1,001 & 1,002 & 6,133 \\
France & 1,031 & 1,012 & 1,024 & 1,005 & 1,035 & 1,051 & 6,158 \\
Hungary & 1,010 & 1,000 & 1,000 & 1,017 & 1,029 & 1,012 & 6,068 \\
Ireland & 1,000 & 1,000 & 1,000 & 1,014 & 1,007 & 1,014 & 6,035 \\
Italy & 1,011 & 1,038 & 1,039 & 1,039 & 1,027 & 1,011 & 6,165 \\
Lithuania & 1,022 & 1,025 & 1,018 & 1,027 & 1,029 & 1,025 & 6,146 \\
Luxembourg & 500 & 502 & 500 & 502 & 503 & 507 & 3,014 \\
Latvia & 1,046 & 1,019 & 1,009 & 1,004 & 1,014 & 1,021 & 6,113 \\
Malta & 500 & 500 & 500 & 500 & 500 & 500 & 3,000 \\
Netherlands & 1127 & 1,020 & 1,000 & 1,004 & 1,012 & 1,008 & 6,171 \\
Poland & 1,000 & 1,000 & 1,000 & 1,000 & 1,000 & 1,000 & 6,000 \\
Portugal & 1,004 & 1,004 & 1,000 & 1,038 & 1,010 & 1,005 & 6,061 \\
Romania & 1,003 & 1,000 & 1,000 & 1,008 & 1,053 & 1,034 & 6,098 \\
Sweden & 1,009 & 1,014 & 1,015 & 1,014 & 1,024 & 1,023 & 6,099 \\
Slovenia & 1,028 & 1,019 & 1,016 & 1,017 & 1,018 & 1,014 & 6,112 \\
Slovakia & 1,015 & 1,003 & 1,055 & 1,047 & 1,040 & 999 & 6,159 \\
United Kingdom & 1,310 & 1,315 & 1,305 & 1,322 & 1,322 & 1,306 & 7,880 \\
\hline Sum & 26,743 & 26,755 & 26,730 & 26,761 & 26,836 & 26,693 & 160,518 \\
\hline \hline
\end{tabular}


Table B.2: Households with fixed-line access by country (\%)

\begin{tabular}{|l||c|c|c|c|c|c|}
\hline \hline Country & 2005 & 2006 & 2007 & 2009 & 2010 & 2011 \\
\hline \hline Austria & 0.69 & 0.58 & 0.58 & 0.50 & 0.48 & 0.47 \\
Belgium & 0.77 & 0.69 & 0.68 & 0.67 & 0.70 & 0.71 \\
Bulgaria & 0.68 & 0.70 & 0.65 & 0.62 & 0.51 & 0.53 \\
Cyprus & 0.91 & 0.88 & 0.89 & 0.84 & 0.85 & 0.77 \\
Czech Republic & 0.54 & 0.44 & 0.35 & 0.24 & 0.17 & 0.19 \\
Germany & 0.88 & 0.89 & 0.87 & 0.89 & 0.88 & 0.88 \\
Denmark & 0.86 & 0.84 & 0.80 & 0.73 & 0.68 & 0.66 \\
Estonia & 0.63 & 0.52 & 0.60 & 0.54 & 0.51 & 0.52 \\
Greece & 0.87 & 0.83 & 0.83 & 0.80 & 0.84 & 0.83 \\
Spain & 0.77 & 0.76 & 0.73 & 0.70 & 0.72 & 0.71 \\
Finland & 0.57 & 0.51 & 0.44 & 0.33 & 0.26 & 0.24 \\
France & 0.86 & 0.80 & 0.85 & 0.90 & 0.89 & 0.90 \\
Hungary & 0.68 & 0.48 & 0.45 & 0.54 & 0.49 & 0.49 \\
Ireland & 0.83 & 0.76 & 0.82 & 0.73 & 0.69 & 0.69 \\
Italy & 0.68 & 0.53 & 0.58 & 0.69 & 0.66 & 0.69 \\
Lithuania & 0.44 & 0.39 & 0.38 & 0.42 & 0.36 & 0.35 \\
Luxembourg & 0.96 & 0.95 & 0.97 & 0.93 & 0.93 & 0.91 \\
Latvia & 0.56 & 0.47 & 0.52 & 0.48 & 0.49 & 0.39 \\
Malta & 0.98 & 0.97 & 0.96 & 0.98 & 0.98 & 0.96 \\
Netherlands & 0.97 & 0.94 & 0.93 & 0.91 & 0.91 & 0.88 \\
Poland & 0.71 & 0.69 & 0.65 & 0.55 & 0.49 & 0.46 \\
Portugal & 0.56 & 0.63 & 0.43 & 0.54 & 0.61 & 0.62 \\
Romania & 0.53 & 0.42 & 0.47 & 0.45 & 0.42 & 0.45 \\
Sweden & 1.00 & 0.98 & 0.98 & 0.99 & 0.98 & 0.99 \\
Slovenia & 0.87 & 0.87 & 0.84 & 0.83 & 0.84 & 0.78 \\
Slovakia & 0.59 & 0.53 & 0.49 & 0.41 & 0.38 & 0.32 \\
United Kingdom & 0.90 & 0.88 & 0.87 & 0.82 & 0.87 & 0.86 \\
\hline \hline
\end{tabular}


Table B.3: Households with mobile access by country (\%)

\begin{tabular}{|l||c|c|c|c|c|c|}
\hline \hline Country & 2005 & 2006 & 2007 & 2009 & 2010 & 2011 \\
\hline \hline Austria & 0.80 & 0.82 & 0.89 & 0.90 & 0.92 & 0.93 \\
Belgium & 0.81 & 0.85 & 0.85 & 0.88 & 0.91 & 0.89 \\
Bulgaria & 0.47 & 0.53 & 0.62 & 0.77 & 0.82 & 0.78 \\
Cyprus & 0.76 & 0.72 & 0.83 & 0.90 & 0.93 & 0.96 \\
Czech Republic & 0.88 & 0.90 & 0.93 & 0.94 & 0.96 & 0.96 \\
Germany & 0.75 & 0.78 & 0.81 & 0.80 & 0.85 & 0.87 \\
Denmark & 0.85 & 0.85 & 0.91 & 0.92 & 0.95 & 0.95 \\
Estonia & 0.75 & 0.82 & 0.85 & 0.90 & 0.93 & 0.92 \\
Greece & 0.68 & 0.70 & 0.75 & 0.81 & 0.90 & 0.91 \\
Spain & 0.74 & 0.76 & 0.76 & 0.86 & 0.87 & 0.87 \\
Finland & 0.92 & 0.91 & 0.93 & 0.94 & 0.96 & 0.95 \\
France & 0.75 & 0.75 & 0.77 & 0.82 & 0.85 & 0.88 \\
Hungary & 0.68 & 0.68 & 0.75 & 0.80 & 0.86 & 0.85 \\
Ireland & 0.82 & 0.86 & 0.89 & 0.92 & 0.94 & 0.94 \\
Italy & 0.89 & 0.89 & 0.92 & 0.95 & 0.93 & 0.94 \\
Lithuania & 0.70 & 0.77 & 0.82 & 0.90 & 0.93 & 0.93 \\
Luxembourg & 0.86 & 0.88 & 0.91 & 0.90 & 0.95 & 0.95 \\
Latvia & 0.72 & 0.79 & 0.86 & 0.91 & 0.95 & 0.95 \\
Malta & 0.73 & 0.80 & 0.79 & 0.85 & 0.89 & 0.82 \\
Netherlands & 0.88 & 0.90 & 0.91 & 0.94 & 0.95 & 0.94 \\
Poland & 0.59 & 0.65 & 0.72 & 0.78 & 0.84 & 0.82 \\
Portugal & 0.64 & 0.77 & 0.77 & 0.81 & 0.84 & 0.85 \\
Romania & 0.50 & 0.62 & 0.66 & 0.74 & 0.85 & 0.81 \\
Sweden & 0.95 & 0.92 & 0.93 & 0.93 & 0.95 & 0.94 \\
Slovenia & 0.87 & 0.82 & 0.85 & 0.91 & 0.91 & 0.92 \\
Slovakia & 0.73 & 0.80 & 0.83 & 0.91 & 0.91 & 0.92 \\
United Kingdom & 0.80 & 0.81 & 0.85 & 0.85 & 0.90 & 0.88 \\
\hline \hline
\end{tabular}


Table B.4: Households with fixed-line and mobile access by country (\%)

\begin{tabular}{|l||c|c|c|c|c|c|}
\hline \hline Country & 2005 & 2006 & 2007 & 2009 & 2010 & 2011 \\
\hline \hline Austria & 0.51 & 0.43 & 0.49 & 0.41 & 0.41 & 0.40 \\
Belgium & 0.60 & 0.57 & 0.56 & 0.56 & 0.62 & 0.62 \\
Bulgaria & 0.33 & 0.37 & 0.44 & 0.47 & 0.41 & 0.39 \\
Cyprus & 0.68 & 0.60 & 0.72 & 0.74 & 0.78 & 0.73 \\
Czech Republic & 0.45 & 0.37 & 0.31 & 0.21 & 0.16 & 0.18 \\
Germany & 0.65 & 0.68 & 0.69 & 0.70 & 0.74 & 0.76 \\
Denmark & 0.71 & 0.71 & 0.72 & 0.65 & 0.63 & 0.61 \\
Estonia & 0.44 & 0.39 & 0.49 & 0.47 & 0.46 & 0.46 \\
Greece & 0.57 & 0.55 & 0.59 & 0.62 & 0.74 & 0.74 \\
Spain & 0.54 & 0.56 & 0.54 & 0.59 & 0.60 & 0.60 \\
Finland & 0.49 & 0.43 & 0.37 & 0.28 & 0.23 & 0.19 \\
France & 0.62 & 0.58 & 0.64 & 0.73 & 0.74 & 0.78 \\
Hungary & 0.43 & 0.30 & 0.31 & 0.39 & 0.41 & 0.40 \\
Ireland & 0.67 & 0.65 & 0.72 & 0.66 & 0.64 & 0.64 \\
Italy & 0.58 & 0.47 & 0.52 & 0.65 & 0.61 & 0.65 \\
Lithuania & 0.26 & 0.29 & 0.29 & 0.36 & 0.31 & 0.30 \\
Luxembourg & 0.82 & 0.83 & 0.87 & 0.83 & 0.88 & 0.86 \\
Latvia & 0.37 & 0.36 & 0.42 & 0.42 & 0.46 & 0.37 \\
Malta & 0.72 & 0.77 & 0.76 & 0.83 & 0.87 & 0.79 \\
Netherlands & 0.85 & 0.84 & 0.84 & 0.85 & 0.87 & 0.83 \\
Poland & 0.41 & 0.42 & 0.43 & 0.39 & 0.38 & 0.34 \\
Portugal & 0.33 & 0.46 & 0.33 & 0.42 & 0.51 & 0.51 \\
Romania & 0.28 & 0.28 & 0.32 & 0.33 & 0.35 & 0.36 \\
Sweden & 0.95 & 0.91 & 0.92 & 0.92 & 0.93 & 0.92 \\
Slovenia & 0.75 & 0.70 & 0.72 & 0.75 & 0.76 & 0.70 \\
Slovakia & 0.40 & 0.39 & 0.37 & 0.35 & 0.31 & 0.27 \\
United Kingdom & 0.71 & 0.71 & 0.73 & 0.68 & 0.78 & 0.75 \\
\hline \hline
\end{tabular}


Table B.5: Choice models for voice and internet services: household characteristics effect

\begin{tabular}{|c|c|c|c|c|c|c|c|}
\hline & \multicolumn{3}{|c|}{ Base model + Incumbent } & \multicolumn{4}{|c|}{ Base model + Broadband } \\
\hline & Mobile & Fixed-line & Mobile+Fixed $(\gamma)$ & Mobile & Fixed-line & Mobile+Fixed $(\gamma)$ & Broadband \\
\hline Living in city & $\begin{array}{c}0.749^{* * *} \\
(0.059)\end{array}$ & $\begin{array}{c}0.547^{* * *} \\
(0.059)\end{array}$ & $\begin{array}{c}-0.479^{* * *} \\
(0.065)\end{array}$ & $\begin{array}{c}0.816^{* * *} \\
(0.045)\end{array}$ & $\begin{array}{c}0.648^{* * *} \\
(0.046)\end{array}$ & $\begin{array}{c}-0.602^{* * *} \\
(0.048)\end{array}$ & $\begin{array}{c}0.235^{* * *} \\
(0.017)\end{array}$ \\
\hline Living in town & $\begin{array}{c}0.496^{* * *} \\
(0.049)\end{array}$ & $\begin{array}{c}0.253^{* * *} \\
(0.049)\end{array}$ & $\begin{array}{c}-0.335^{* * *} \\
(0.055)\end{array}$ & $\begin{array}{c}0.550^{* * * *} \\
(0.036)\end{array}$ & $\begin{array}{c}0.241^{* * *} \\
(0.037)\end{array}$ & $\begin{array}{c}-0.404^{* * *} \\
(0.039)\end{array}$ & $\begin{array}{c}0.186^{* * *} \\
(0.015)\end{array}$ \\
\hline Male & $\begin{array}{c}-0.154^{* * *} \\
(0.046)\end{array}$ & $\begin{array}{c}-0.401^{* * * *} \\
(0.046)\end{array}$ & $\begin{array}{c}0.448^{* * *} \\
(0.051)\end{array}$ & $\begin{array}{c}-0.394^{* * *} \\
(0.033)\end{array}$ & $\begin{array}{c}-0.598^{* * *} \\
(0.034)\end{array}$ & $\begin{array}{c}0.500^{* * *} \\
(0.036)\end{array}$ & $\begin{array}{c}0.249^{* * *} \\
(0.014)\end{array}$ \\
\hline Married & $\begin{array}{c}0.331^{* * *} \\
(0.052)\end{array}$ & $\begin{array}{c}0.267^{* * *} \\
(0.052)\end{array}$ & $\begin{array}{l}-0.052 \\
(0.058)\end{array}$ & $\begin{array}{c}0.412^{* * *} \\
(0.038)\end{array}$ & $\begin{array}{c}0.343^{* * *} \\
(0.040)\end{array}$ & $\begin{array}{c}-0.200^{* * *} \\
(0.042)\end{array}$ & $\begin{array}{c}0.184^{* * *} \\
(0.016)\end{array}$ \\
\hline Household size & $\begin{array}{c}0.069^{* *} \\
(0.029)\end{array}$ & $\begin{array}{c}0.336^{* * *} \\
(0.031)\end{array}$ & $\begin{array}{c}0.086^{* * *} \\
(0.033)\end{array}$ & $\begin{array}{c}0.120^{* * *} \\
(0.022)\end{array}$ & $\begin{array}{c}0.266^{* * *} \\
(0.024)\end{array}$ & $\begin{array}{c}0.031 \\
(0.025)\end{array}$ & $\begin{array}{c}0.310^{* * *} \\
(0.008)\end{array}$ \\
\hline Number of kids & $\begin{array}{c}-0.124^{* *} \\
(0.060)\end{array}$ & $\begin{array}{c}-0.263^{* * *} \\
(0.066)\end{array}$ & $\begin{array}{l}0.125^{*} \\
(0.070)\end{array}$ & $\begin{array}{c}-0.138^{* * *} \\
(0.046)\end{array}$ & $\begin{array}{c}-0.293^{* * *} \\
(0.053)\end{array}$ & $\begin{array}{c}0.147^{* * *} \\
(0.055)\end{array}$ & $\begin{array}{c}0.033^{* *} \\
(0.017)\end{array}$ \\
\hline Age $>24$ and $\leq 34$ & $\begin{array}{c}2.649^{* * *} \\
(0.137)\end{array}$ & $\begin{array}{c}-2.028^{* * *} \\
(0.170)\end{array}$ & $\begin{array}{c}0.201 \\
(0.181)\end{array}$ & $\begin{array}{c}1.969^{* * *} \\
(0.097)\end{array}$ & $\begin{array}{c}-2.443^{* * *} \\
(0.124)\end{array}$ & $\begin{array}{c}0.125 \\
(0.128)\end{array}$ & $\begin{array}{c}1.347^{* * *} \\
(0.039)\end{array}$ \\
\hline Age $>34$ and $\leq 44$ & $\begin{array}{c}2.490^{* * *} \\
(0.110)\end{array}$ & $\begin{array}{c}-1.727^{* * *} \\
(0.122)\end{array}$ & $\begin{array}{l}-0.031 \\
(0.134)\end{array}$ & $\begin{array}{c}2.028^{* * *} \\
(0.081)\end{array}$ & $\begin{array}{c}-2.254^{* * *} \\
(0.094)\end{array}$ & $\begin{array}{l}-0.173^{*} \\
(0.098)\end{array}$ & $\begin{array}{c}1.298^{* * *} \\
(0.032)\end{array}$ \\
\hline Age $>44$ and $\leq 54$ & $\begin{array}{c}1.860^{* * *} \\
(0.104)\end{array}$ & $\begin{array}{c}-1.269^{* * *} \\
(0.107)\end{array}$ & $\begin{array}{l}-0.078 \\
(0.121)\end{array}$ & $\begin{array}{c}1.526^{* * *} \\
(0.076)\end{array}$ & $\begin{array}{c}-1.744^{* * *} \\
(0.082)\end{array}$ & $\begin{array}{c}-0.239^{* * *} \\
(0.087)\end{array}$ & $\begin{array}{c}1.272^{* * *} \\
(0.031)\end{array}$ \\
\hline Age $>54$ and $\leq 64$ & $\begin{array}{c}1.404^{* * *} \\
(0.089)\end{array}$ & $\begin{array}{c}-0.732^{* * *} \\
(0.086)\end{array}$ & $\begin{array}{l}-0.192^{*} \\
(0.102)\end{array}$ & $\begin{array}{c}1.110^{* * *} \\
(0.063)\end{array}$ & $\begin{array}{c}-1.182^{* * *} \\
(0.066)\end{array}$ & $\begin{array}{c}-0.269^{* * *} \\
(0.071)\end{array}$ & $\begin{array}{c}1.141^{* * *} \\
(0.029)\end{array}$ \\
\hline Age $>64$ & $\begin{array}{c}1.016^{* * * *} \\
(0.069)\end{array}$ & $\begin{array}{c}-0.332^{* * *} \\
(0.062)\end{array}$ & $\begin{array}{l}-0.050 \\
(0.078)\end{array}$ & $\begin{array}{c}0.924^{* * *} \\
(0.047)\end{array}$ & $\begin{array}{c}-0.566^{* * *} \\
(0.047)\end{array}$ & $\begin{array}{c}-0.235^{* * *} \\
(0.053)\end{array}$ & $\begin{array}{c}0.793^{* * *} \\
(0.024)\end{array}$ \\
\hline Education years 15 - & $\begin{array}{c}0.656^{* * *} \\
(0.110)\end{array}$ & $\begin{array}{c}0.502^{* * *} \\
(0.094)\end{array}$ & $\begin{array}{c}-0.421^{* * *} \\
(0.128)\end{array}$ & $\begin{array}{c}0.417^{* * *} \\
(0.073)\end{array}$ & $\begin{array}{c}0.328^{* * *} \\
(0.070)\end{array}$ & $\begin{array}{l}-0.031 \\
(0.083)\end{array}$ & $\begin{array}{c}-0.505^{* * *} \\
(0.048)\end{array}$ \\
\hline Education years $>15$ and $\leq 20$ & $\begin{array}{c}1.326^{* * *} \\
(0.110)\end{array}$ & $\begin{array}{c}0.986^{* * * *} \\
(0.098)\end{array}$ & $\begin{array}{c}-0.520^{* * *} \\
(0.129)\end{array}$ & $\begin{array}{c}1.136^{* * *} \\
(0.073)\end{array}$ & $\begin{array}{c}0.687^{* * *} \\
(0.072)\end{array}$ & $\begin{array}{c}-0.264^{* * *} \\
(0.084)\end{array}$ & $\begin{array}{c}0.323^{* * *} \\
(0.046)\end{array}$ \\
\hline Education years $20+$ & $\begin{array}{c}1.629^{* * *} \\
(0.123)\end{array}$ & $\begin{array}{c}1.373^{* * *} \\
(0.113)\end{array}$ & $\begin{array}{c}-0.541^{* * *} \\
(0.141)\end{array}$ & $\begin{array}{c}1.691^{* * *} \\
(0.090)\end{array}$ & $\begin{array}{c}1.126^{* * *} \\
(0.090)\end{array}$ & $\begin{array}{c}-0.628^{* * *} \\
(0.100)\end{array}$ & $\begin{array}{c}1.048^{* * *} \\
(0.047)\end{array}$ \\
\hline Profession: housekeeping & $\begin{array}{l}-0.077 \\
(0.102)\end{array}$ & $\begin{array}{c}-0.496^{* * *} \\
(0.110)\end{array}$ & $\begin{array}{c}0.086 \\
(0.123)\end{array}$ & $\begin{array}{l}-0.069 \\
(0.073)\end{array}$ & $\begin{array}{c}-0.596^{* * *} \\
(0.083)\end{array}$ & $\begin{array}{c}0.264^{* * *} \\
(0.088)\end{array}$ & $\begin{array}{l}-0.027 \\
(0.033)\end{array}$ \\
\hline Prefession: student & $\begin{array}{c}1.798^{* * *} \\
(0.188)\end{array}$ & $\begin{array}{c}1.322^{* * * *} \\
(0.222)\end{array}$ & $\begin{array}{l}-0.346 \\
(0.242)\end{array}$ & $\begin{array}{c}1.910^{* * *} \\
(0.147)\end{array}$ & $\begin{array}{c}0.958^{* * *} \\
(0.177)\end{array}$ & $\begin{array}{c}-0.417^{* *} \\
(0.184)\end{array}$ & $\begin{array}{c}1.536^{* * *} \\
(0.059)\end{array}$ \\
\hline Profession: retired & $\begin{array}{c}0.204^{* *} \\
(0.092)\end{array}$ & $\begin{array}{c}0.039 \\
(0.086)\end{array}$ & $\begin{array}{l}-0.140 \\
(0.101)\end{array}$ & $\begin{array}{c}0.189^{* * *} \\
(0.066)\end{array}$ & $\begin{array}{c}0.042 \\
(0.066)\end{array}$ & $\begin{array}{l}-0.026 \\
(0.072)\end{array}$ & $\begin{array}{l}0.057^{*} \\
(0.030)\end{array}$ \\
\hline Profession: office employee & $\begin{array}{c}1.224^{* * *} \\
(0.163)\end{array}$ & $\begin{array}{c}0.604^{* * *} \\
(0.174)\end{array}$ & $\begin{array}{l}-0.252 \\
(0.181)\end{array}$ & $\begin{array}{c}1.465^{* * *} \\
(0.141)\end{array}$ & $\begin{array}{c}0.630^{* * *} \\
(0.149)\end{array}$ & $\begin{array}{c}-0.616^{* * *} \\
(0.152)\end{array}$ & $\begin{array}{c}0.674^{* * *} \\
(0.032)\end{array}$ \\
\hline Profession: professional & $\begin{array}{c}1.198^{* * *} \\
(0.210)\end{array}$ & $\begin{array}{c}0.248 \\
(0.229)\end{array}$ & $\begin{array}{c}0.180 \\
(0.238)\end{array}$ & $\begin{array}{c}0.955^{* * *} \\
(0.179)\end{array}$ & $\begin{array}{l}-0.091 \\
(0.194)\end{array}$ & $\begin{array}{c}0.157 \\
(0.197)\end{array}$ & $\begin{array}{c}1.075^{* * *} \\
(0.043)\end{array}$ \\
\hline Profession: manual worker & $\begin{array}{c}0.620^{* * *} \\
(0.097)\end{array}$ & $\begin{array}{c}0.030 \\
(0.101)\end{array}$ & $\begin{array}{c}-0.255^{* *} \\
(0.111)\end{array}$ & $\begin{array}{c}0.775^{* * *} \\
(0.073)\end{array}$ & $\begin{array}{c}0.092 \\
(0.078)\end{array}$ & $\begin{array}{c}-0.324^{* * *} \\
(0.082)\end{array}$ & $\begin{array}{c}0.125^{* * *} \\
(0.029)\end{array}$ \\
\hline Profession: proprietor & $\begin{array}{c}1.393^{* * *} \\
(0.209)\end{array}$ & $\begin{array}{c}0.891^{* * *} \\
(0.219)\end{array}$ & $\begin{array}{c}-0.493^{* *} \\
(0.227)\end{array}$ & $\begin{array}{c}2.036^{* * *} \\
(0.209)\end{array}$ & $\begin{array}{c}1.266^{* * *} \\
(0.216)\end{array}$ & $\begin{array}{c}-1.115^{* * *} \\
(0.219)\end{array}$ & $\begin{array}{c}0.647^{* * *} \\
(0.038)\end{array}$ \\
\hline Profession: manager & $\begin{array}{c}1.037^{* * * *} \\
(0.177)\end{array}$ & $\begin{array}{c}0.485^{* * *} \\
(0.187)\end{array}$ & $\begin{array}{l}-0.104 \\
(0.194)\end{array}$ & $\begin{array}{c}1.202^{* * *} \\
(0.170)\end{array}$ & $\begin{array}{c}0.572^{* * *} \\
(0.176)\end{array}$ & $\begin{array}{c}-0.605^{* * *} \\
(0.179)\end{array}$ & $\begin{array}{c}1.048^{* * * *} \\
(0.036)\end{array}$ \\
\hline Profession: farmer & $\begin{array}{c}-0.398^{* *} \\
(0.173)\end{array}$ & $\begin{array}{c}0.184 \\
(0.161)\end{array}$ & $\begin{array}{c}0.170 \\
(0.199)\end{array}$ & $\begin{array}{l}-0.074 \\
(0.115)\end{array}$ & $\begin{array}{c}0.396^{* * *} \\
(0.119)\end{array}$ & $\begin{array}{c}0.113 \\
(0.132)\end{array}$ & $\begin{array}{c}-0.329 * * * \\
(0.062)\end{array}$ \\
\hline Profession: travelling & $\begin{array}{c}1.177^{* * * *} \\
(0.139)\end{array}$ & $\begin{array}{c}0.550^{* * * *} \\
(0.147)\end{array}$ & $\begin{array}{c}-0.471^{* * *} \\
(0.154)\end{array}$ & $\begin{array}{c}1.393^{* * *} \\
(0.114)\end{array}$ & $\begin{array}{c}0.589^{* * *} \\
(0.121)\end{array}$ & $\begin{array}{c}-0.748^{* * *} \\
(0.124)\end{array}$ & $\begin{array}{c}0.547^{* * * *} \\
(0.030)\end{array}$ \\
\hline $\begin{array}{l}\text { Observations } \\
\text { Households }\end{array}$ & $\begin{array}{c}405,902 \\
53,199\end{array}$ & & & $\begin{array}{c}2,980,416 \\
156,864\end{array}$ & & & \\
\hline
\end{tabular}

(i) Base model + Incumbent: choices of voice connections from incumbent vs. competitor; (ii) Base model + Broadband: choices of voice and broadband connections.

Standard errors in parentheses, ${ }^{* * *} p<0.01,{ }^{* *} p<0.05,{ }^{*} p<0.1$ 